\title{
"دور أبعاد الإبداع المالي في تحقيق متطلبات النجاح المالي" \\ دراسة استطلاعية لاراء القيادات الإدارية لعينة من المصارف الأهلية في إقليم كوردستان العراق \\ حكمت رشيد سلطان و سامي عبدالله عزب2
}

1قسم ادارة الأعمال، كلية الادارة والاقتصاد، جامعة دهوك، أقليم كوردستان العراق- العراق.

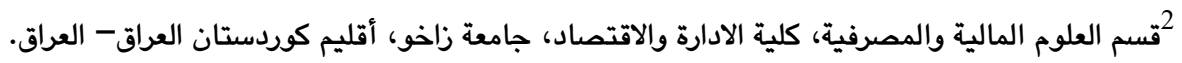

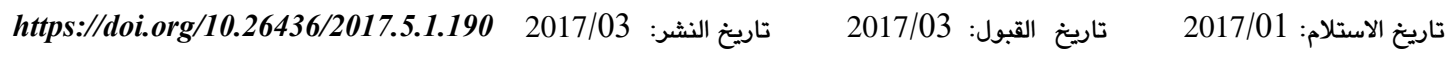

الملخص:

شهدت البيئة العالمية في العقدين الأخيرين العديد من التطورات و التغيرات من بينها : ظاهرة العولمة وتقدم تكنولوجيا المعلومات والاقتصاد المبني على المعرفة والإبداع، وقد فرضت هذه التغيرات تحديات جديدة على منظمات الأعمال وخاصة المصارف و أصبح التحدي الرئيس الذي يواجه تلك المنظمات في ظل عولمة النشاط الاقتصادي ،هو كيفية زيادة قدراتها التنافسية، والمحافظة

عليها لمواكبة تلك التغيرات، ومن ثم تحقيق النجاح فيها.

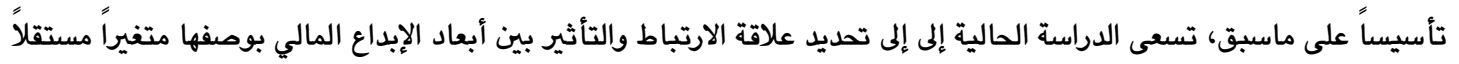

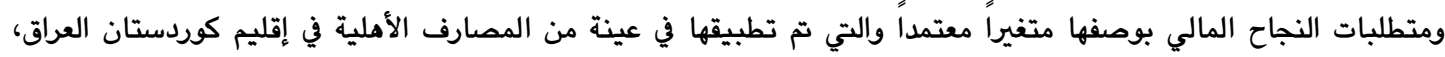

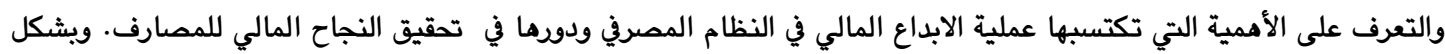

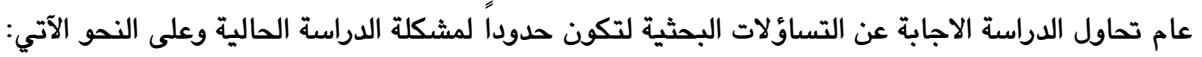

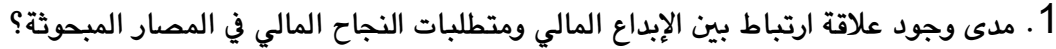

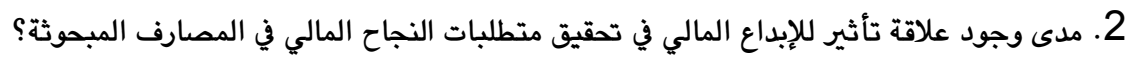
وتوصلت الدراسة لعدد من الاستنتاجات من أهمها: أ. أظهرت نتائج التحليل عن وجود علاقة ارتباط معنوية بين كل بُعد من أبعاد الإبداع المالي والنجاح المالي على المستوى الكلي لمصارف عينة الدراسة.

ب. هناك تأثير معنوي للإبداع المالي أجمالاً في النجاح المالي على مستوى المصارف عينة الدراسة.

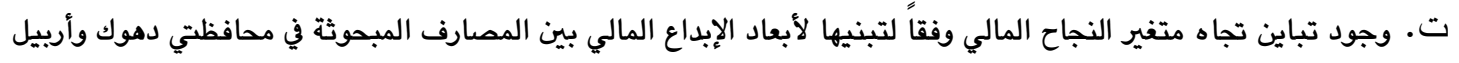

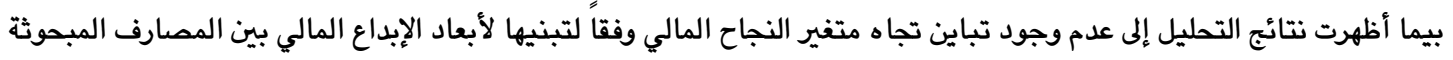

\section{في محافظة السليمانية.}

ووضعت الدراسة عدداً من المقترحات التي تتوائم مع النتائج التي توصلت إليها الدراسة الحالية فضلاً عن اقتراح مجموعة من

الدراسات المستقبلية للباحثين في هذا المجال الكلمات الدالة: أبعاد الإبداع المالي، متطلبات النجاح المالي، المصارف الأهلية، إقليم كوردستان العراق.

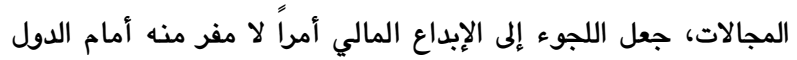

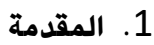

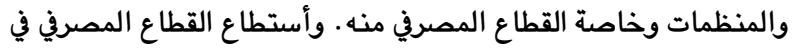

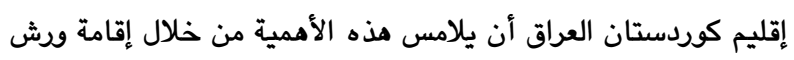

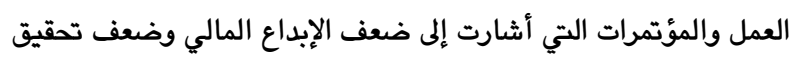

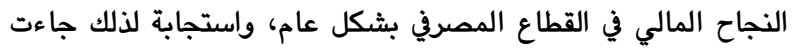

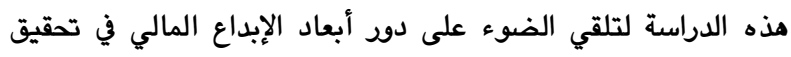

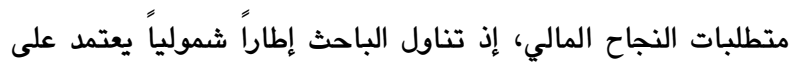

يتطلب استمرار التقدم العلمي والتطور التقني الذي تحقق في مختلف

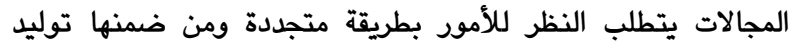

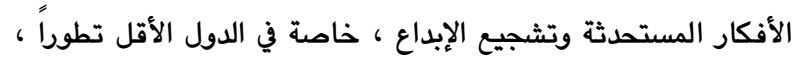

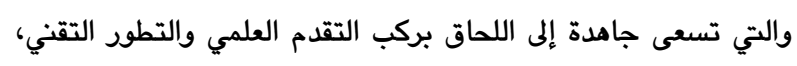
وأن القرن الواحد والعشرون بما يتضمنه من تقدم وتطور في كافة 
وهذه الحلول يتطلب فترة وجيزة من الانظمة الجديدة ومن ثم تأسيس أسواق ومنظمات مالية جديدة متخصصة في مذه التطورات الجديدة

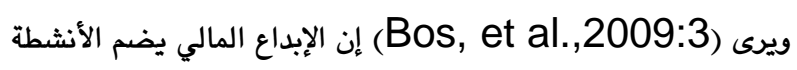
التي تقلل من تكاليف المنظمة المالية داخلياً وخارجياً وكذلك تقلل المخاطرة ويوفر احتياجات الزيائن على نطاق واسع من منتجات جديدة على سبيل المثال (أجهزة الصراف الآلي والائتمان وبطاقات السحب الآلي، تعديل معدل القروض العقارية)، وعمليات الانتاج على سبيل المثال ( المدفوعات الالكترونية الجديدة وحفظ السجلات وجمع المعلومات ونشرما عبر أجهزة الكومبيوتر والاتصالات وتوريق القروض والخدمات المالية الاخرى )، والأشكال التنظيمية على سبيل المثال ( بنوك الانترنيت والبنوك المتنوعة بين الدول والخدمات المالية التقليدية وغير التقليدية ). ويوضح (Bruno \& Lippe,2012:16) وغير النقل الإبداع المالي قد ادخل طرقاً جديدة لأكتساب الميزة التبادلية من الاحتياجات الكمالية على سبيل المثال الرغبة في اقتراض المال ورفع رأس المال الاستثماري أو تعويض الخطر هذا من جهة ، والرغبة في الاقراض واستثمار الاموال

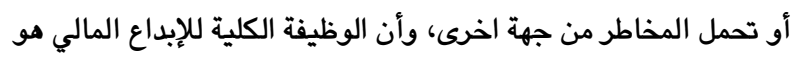
الحد من عيوب السوق المالية ويساعد على سد الفجوة المتاحة للسلع أو الخدمات للمستهلكين ( على سبيل المثال من خلال توفير آلية جديدة للدفع عبر الانترنيت أو التسعير من خلال التكنولوجيا المبتكرة

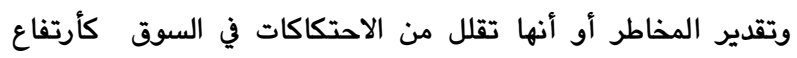
تكاليف معاملات بعض المنتجات. ويعرفه (Avais,2014:1) بأنه تقديم أدوات جديدة للمستثمرين لم يتم تقديمها لهم من قبل ، حيث واصلت الأسواق المالية إنتاج العديد من المنتجات المالية الجديدة بما في ذلك العديد من المشتقات المالية والأشكال الجديدة لها وكذلك منتجات نقل المخاطر البديلة والصناديق المتداولة في البوصة. واستناداً الى ما سبق فأن التعريف الاجرائي للإبداع المالي هو" تطبيق أفكار جديدة في المنظمات المالية والمصرفية ويتضمن تطورات جديدة

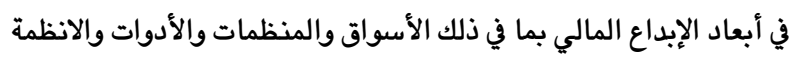
ويرافقه في ذلك تطبيق التكنولوجيا المتقدمة وكونها حالة جديدة من قبل المستخدم النهائي وذلك بهدف النجاح المستمر لهذه المنظمات".

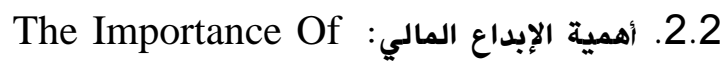
Financial Innovation للإبداع المالي أهمية كبيرة في المنظمات المالية والمصرفية، ويمكن تلخيص أهمية الإبداع المالي في النقاط الاتية : 1. الإبداع مو ظاهرة مهمة في أي قطاع من القطاعات الاقتصادية

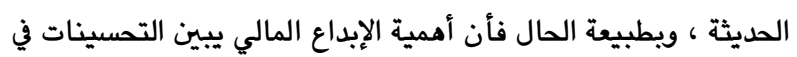
القطاع المالي ولها تداعيات إيجابيىة مباشرة في النواحي الإقتصادية، وعلاوة على ذلك فأن الإبداع المالي يشجع على المزيد من الإدخار
طروحات الكتاب والباحثين في الإدارة المالية وإدارة الأعمال ، وإدارة الأسواق المالية وأستهدف الدراسة بناء إطار ميداني لدور أبعاد الإبداع المالي في تدقيق النجاح المالي عن طريق وصف المتغيرات وتشخيصها فضلاً عن تحليل علاقات الارتباط والتأثير بين متغيرات الدراسة الرئيسة، وتقديم المقترحات لمصارف عينة الدراسة والباحثين في هذا الموضوع مستقبلاً. وتأسيساً على ماتقدم فقد تم بناء أنموذج افتراضي يحدد طبيعة العلاقة بين المتغير المستقل (الإبداع المالي)، والمتغير المعتمد (النجاح المالي)، وانبثقت منه مجموعة من الفرضيات الرئيسة والفرعية التي اختبرت من خلال أساليب احصائية للبيانات والمعلومات المجمعة عن المصارف عينة الدراسة في أقليم كوردستان العراق ، وأكدت نتائجها دعمها لفرضيات الدراسة وأهدافها وسريان أنموذجها. 2. المبحث الاول: مفهوم الإبدع المالي وأهميته وأبعاده

The Concept Of : مفهوم الإبداع المالي: مone Financial Innovation للإبداع دور مهم في التنمية الإقتصادية وهذا الأمر لاجدال فيه ،

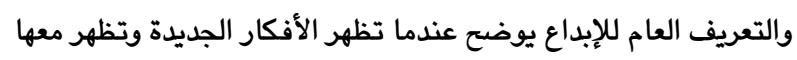
الحلول والأدوات من أجل تغيير شروط الأعمال التجارية وتحسين أوضاعها وتطبيق الإبداع يزيد من القدرة التنافسية للأعمال ويخلق قيمة

لاصحابها (Dabic,2011:196). ويشير (Btach:2011:17) إلى أن الإبداع المالي له تاريخ طويل في التطور ويمكن توضيح ذلك بأن ظهور الأدوات المالية (الاسهم والسندات) والاسواق المالية (أسواق الاسهم والسندات التقليدية) والمنظمات المالية (المصارف التقليدية) في فترة القرن السابع والثامن عشر يمكن تصنيفها على أنها إبداعات مالية، وفي القرن السابع والثامن

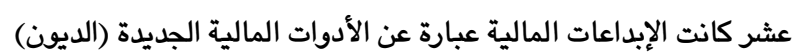
في ذلك الوقت يرتبط بالأسواق ذات السيولة العالية والتي وجدت لجمع رأس المال المطلوب لتمويل الحملات الاستكشافية عبر المحيطات والرحلات التجارية، ثم في القرن التاسع عشر فإن المصارف الإستثمارية وياستخدام وسائل المحاسبة الجديدة بدأت بتقييم ربحية الشركات السكك الحديدية وتزويدهم بمصادر التمويل، ويعد ذلك في القرن العشرين ظهر شركات الملكية الخاصة والتي أخذت بتحليل وتمويل المشاريع التي تقدم الحلول للمشاكل التكنولوجية. ويرى (4) Gubler,2010:1-49) بأنه يمكن تعريف الإبداع المالي

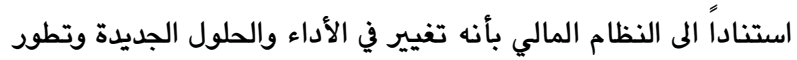

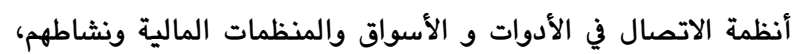
والعلاقة بين مذه المجموعة من الابتكارات المالية متعدد الابعاد يمكن وصفها بأنها دوامة الإبداع وهذا يعني أن المنظمات المالية الجديدة تؤدي الى خلق أدوات مالية جديدة ويتم تداولها في أسواق مالية جديدة 


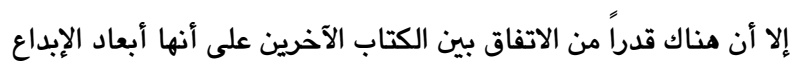

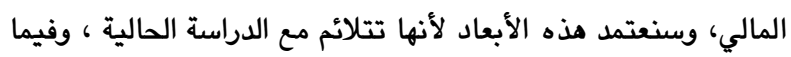

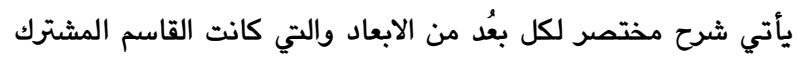

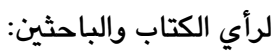

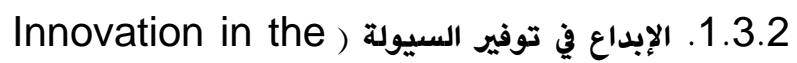
Availability of Liquidity بأنهّا قدرة المصرف على مواجهة إلتزاماته المالية، والتي تتكون بشكل كبير من تلبية طلبات المودّعين للسحب من الودائع، وتلبية طلبات

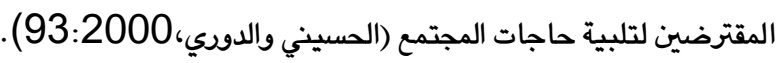
وتُعرف بأنّها قدرة المصرف على تسديد جميع إلتزاماته المالية نقداً،

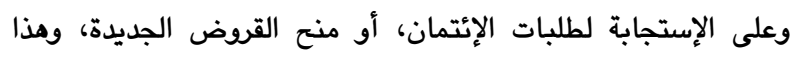

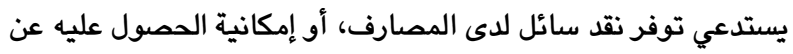

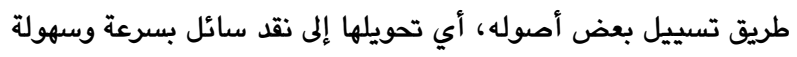

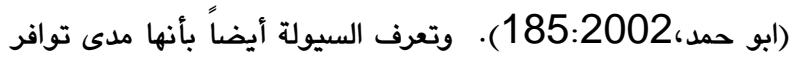
أصول سريعة التحويل إلى نقدية بدون خسائر في قيمتها لمقابلة الديون

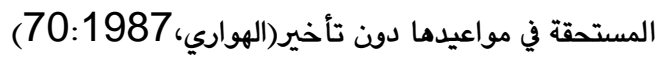
ويرى (Hampel,1994:158) إن احد أهم المهام بالنسبة لأداء المصرف هي قياس وتلبية احتياجاته من السيولة، وأن احتياجات سيولة المصرف يجب أن تكون مقاسه بصورة ديناميكية، وريما تكون

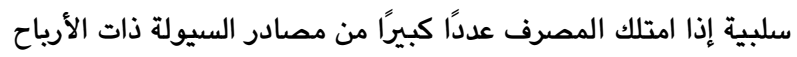

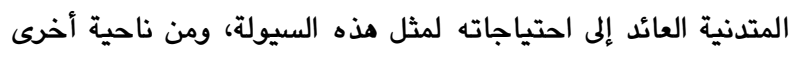

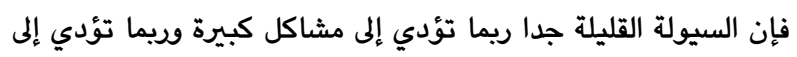

$$
\text { فشل المصرف أيضاً. }
$$

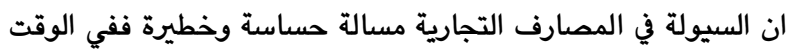

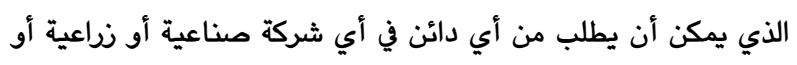

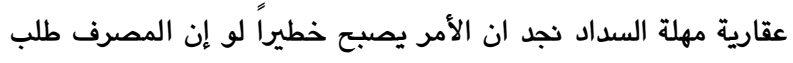

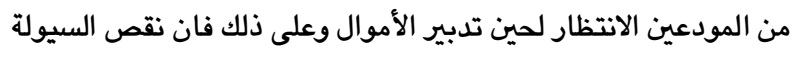

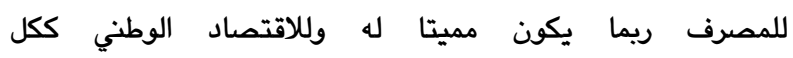

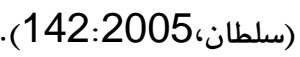
من خلال التعريفات والمفاهيم السابقة يرى الباحثان بأن السيولة في المفهوم المالي تدور حول نشاط محوري، وهو توفير الأموال لمواجهة

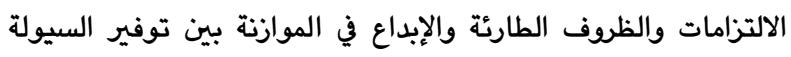
بالكمية المناسبة والتوقيت المناسب وبين الافراط في الاحتفاظ بالسيولة بحيث لايلحق الضرر بمصالح المصرف أو مصالح الزبائن.

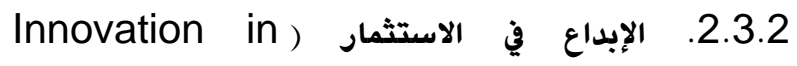
Investment بهدف تحقيق عوائد مستقبلية، فهو علاقة بين الموجود والزمن المستقبلي لتحقيق منفعة معينة، وتحمل مخاطر تنعكس بالخسائر، فالإستثمار ظاهرة كبيرة يمارسها الأفراد والعائلات والمنظمات والدول
والاستثمار، ويمكن أيضاً أن يكون أكثر انتاجية في القرارات الاستثمارية

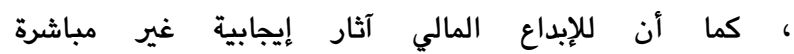
. (Frame\&whit,2002:4) 2. تكمن أهمية الإبداع المالي في مساهمتها في تعزيز الوساطة المالية

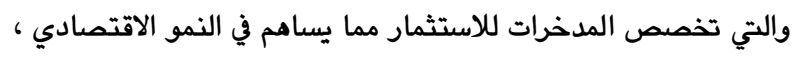

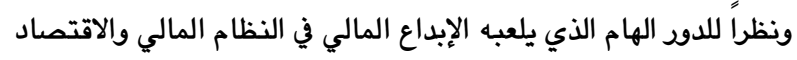

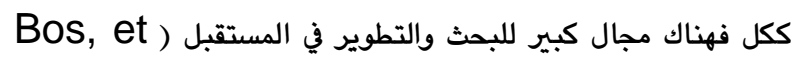
.(al.,2009:4

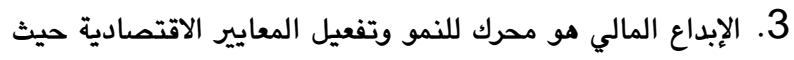
له دود أساس في خلق وظائف جديدة ، وتوفير دخل أعلى ، وتقديم الفرص الاستثمارية، وحل المشاكل الاجتماعية ، والصحية ، والحفاظ

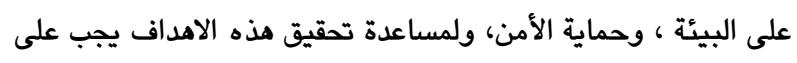

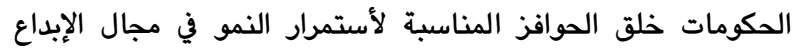

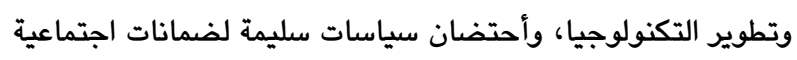

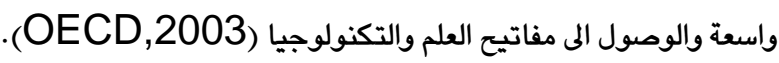

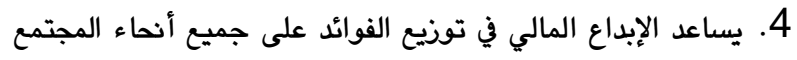
حيث يساهم في خفض الأسعار وصنع سلع وخدمات جديدة على نطاقٍ

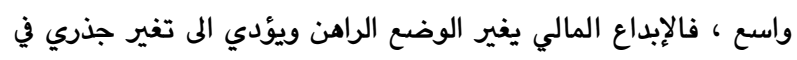

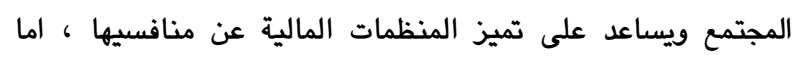
بالنسبة للمستهلك فيؤدي الى تحسينات مفيدة في السلع والذدمات

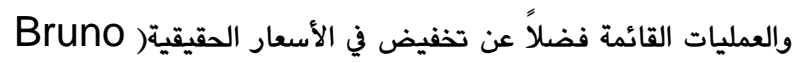
. (\& Lippe,2012:11 5. للإبداع المالي أهمية في تفسير الاداء المصرفي، وأثر الإبداع المالي على الاداء المالي لايزال يساء فهمه بسبب عدم فهم برامج تشغيل الإديل

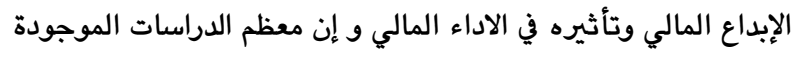

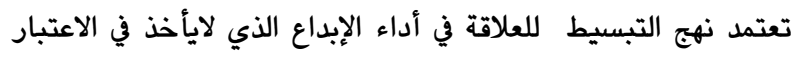

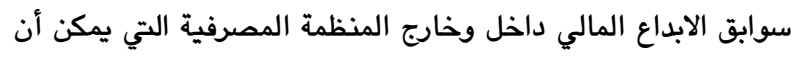

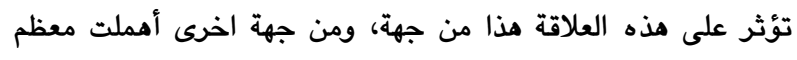

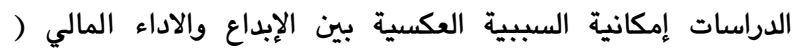
.Nuiruri \& Ngari,2014:52 3.2. أبعاد الابداع المالي: Dimensions of Financial Innovation تناول الكتاب والباحثون أبعاد الإبداع المالي وفق صيخ تتفق في العدد

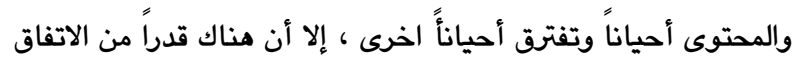

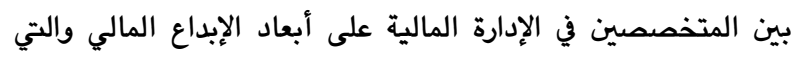

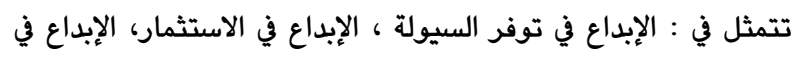

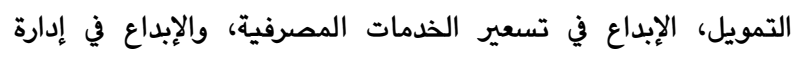

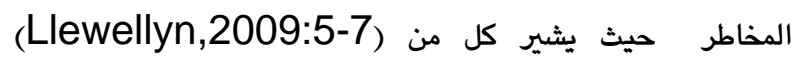

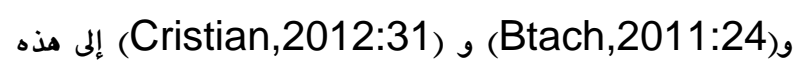
ألابعاد، وعلى الرغم من أن بعض الكتاب يسميها وظائف الإبداع المالي 
بتمويل قصير الأجل، وعلى هذا الاساس فالتمويل أنواع منها التمويل طويل الأجل ومتوسط الأجل وقصير الأجل. وتتمثل الوظائف الرئيسة للمدير المالي في وضع خطط للتمويل والحصول على الموارد المالية وكيفية الحصول عليها ومن ثم استخدام هذه الموارد بشكل يؤدي إلى زيادة فعالية عمليات وإنجازات المنظمة إلى الحد الأقصى ، وهذا يتطلب الإبداع والمعرفة بالأسواق المالية التي تحصل المنظمة من خلالها على الموارد المالية وكيفية الوصول إلى لى قرارات الاستثمار السليمة والفعالة ( ويستون ويرجام، 25:2006). ولضمان الاختيار الأنسب من بين ماهو متاح من مصادر التمويل لابد أن تتوافر لدى الإدارة المالية للمنظمة القدرات الكافية وأن يكون المدير المالي مبدعاً بما فيه الكفاية لتقييم أثر استعمال مصادر التمويل

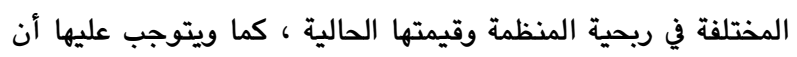
تستقر على أي نوع من مصادر التمويل ، وأن يكون ملماً بجميع مصادر التمويل المتاحة وطبيعة تلك المصادر وميزاتها وعيوبها وكلفة كل منها والاجراءات اللازمة للحصول عليها وهذا يتطلب إبداعاً في هذا المجال لاختيار الأنسب من بين تلك المصادر(عقل، 149:2011). من خلال التعاريف والمفاهيم السابقة يمكن القول أن التمويل هو عبارة عن إتاحة أو تدبير الموارد النقدية للمنظمة في أي وقت تكون هنالك حاجة إليه والتي يتم بموجبها توفر الموارد الحقيقية التي توجه لتكوين

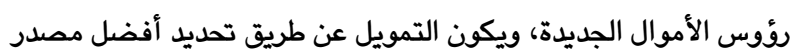
للأموال وذلك بالمقارنة بين مصادره المتاحة.

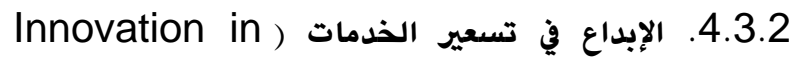
Services pricing): يمثل السعر بالنسبة للزبون تلك القيمة النقدية أو العينية التي تحدد من قبل مقدم الخدمة ثمناً لخدمته وما تمثله من منافع أو فوائد، وينظر للسعر على أنه تلك القوة الشرائية التي يظهرها الزبون للحصول على السلعة أو الخدمة المطلوية

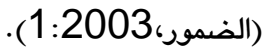

ويرى (الصميدعي ويوسف، 286:2001) بأن "السعر يعبر عن انعكاس أو تجسيد لقيمة الشيء بالنسبة للزبون خلال فترة معينة. ويعرفه (عبيدات،20:2004) بأنه "قيمة المنتج التي يمكن تعديلها صعوداً أو هبوطاً وفقاً لمتغيرات داخلية وخارجية تحيط بعمل المنظمة ويما يتفق وإمكانات الشراء لدى المنتفعين ووفق أذواقهم. ويعرفه (البيجاني،5:1999) بأنه فن ترجمة القيمة في وقت معين ومكان معين للسلع والخدمات المعروضة إلى قيمة نقدية وفقاً للعملة المتداولة في المجتمع مع الأخذ بالاعتبار الظروف الداخلية للمنظمة.

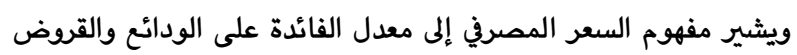
والرسوم والمصروفات الأخرى التي يتحملها المصرف لقاء تقديم الخدمات المصرفية أو العمولات التي يتلقاها المصرف نتيجة تقديمه الخدمات للغير(معلا،153:1994).
بكل تنظيماتها وهو نوع من التحسب للمستقبل ( الجميل،

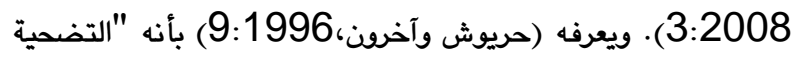

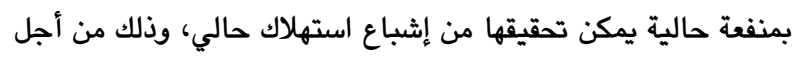
الحصول على منفعة مستقبلية أكبر يمكن تدقيقها من إثباع استهلاك مستقبلي. وينظر (حردان،15:2009) إلى الاستثمار في مجال الادارة المالية على أنه توظيف في أصل من الأصول المالية كالاسهم والسندات والقبولات البنكية وشهادات الإيداع وغيرما ويسمى بالاستثمارات المالية. ويستند تصنيف الاستثمارات إلى معايير أو أسس متعددة، إذ يمكن أن تتباين وفق معيار الزمن فهناك استثمارات طويلة ومتوسطة الأجل نظراً إلى امتلاكها أدوات مالية متداولة في أسواق رأس المال أو أو استثمارات قصيرة الأجل لامتلاكها أدوات متداولة في الأسواق النقدية. وتمتلك المنظمات الاستثمارات لأسباب مختلفة ، فبعض المنظمات كشركات التأمين ويعض المصارف يكون محور نشاطها الاستثمار حيث تمتلك وعاء لإحتواء فوائضها المالية ، في حين أن البعض الآخر يمتلك الاستثمارات ذات الطابع التجاري بقصد تدعيم العلاقات التجارية مع الغير أو بهدف الحصول على مزايا تجارية لها لهائ (الازهري، 15:1998). تأسيساً على ما سبق يتضح أن الاستثمار هو "التخلي عن استخدام

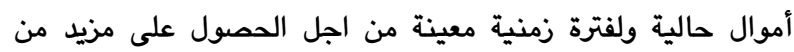
التدفقات النقدية في المستقبل تكون بمثابة تعويض عن الفرصة الضائعة للأموال المستثمرة، وكذلك تعويض عن الانخفاض المتوقع في القوة الشرائية للأموال المستثمرة بسبب التضخم مع إمكانية الحصول

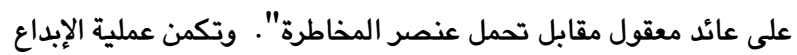
في الاستثمار في محاور متعددة أهمها الموازنة الدقيقة في محتويات الحقيبة الاستثمارية من نقد و أوداق مالية وموجودات متداولة وثابتة، فضلاً عن الإبداع في تقليل المخاطرة من خلال استخدام أدوات مناسبة متلية وتعظيم العوائد. 3.3.2. الإبداع في التمويل(Innovation in Funding): المقصود بالتمويل هو توفير الموارد المالية اللازمة لإنشاء المشروعات الاستثمارية، أو تكوين رؤوس الأموال الجديدة واستخدامها لبناء

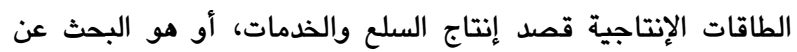
الطرائق المناسبة للحصول على الأموال واختيار وتقييم تلك الطرائق والحصول على المزيج الأفضل بينهما بشكل يناسب كمية ونوعية احتياجات والتزامات المنظمة المالية (خوني وحساني،95:2008). ويرى (الجميل،179:2012) أن التمويل هو توفير الأموال اللازمة لتغطية كلف معينة رأسمالية وتشغيلية ، فأي موجود تقتنيه المنظمة التميل يعد كلفة رأسمالية بحاجة إلى تمويل معين يلائمه في الأجل، ويمول بتمويل طويل الأجل، وأي نفقة تتحملها المنظمة تعد كلفة تشغيلية بحاجة إلى تمويل معين يلائمها في الأجل فيكون تمويل النفقة تلك 
المخاطر وفق تصنيفات محددة متفق عليها في المصرف لما ينطوي الإبداع في ادارة المخاطر على الرقابة والسيطرة عليها بهدف تقليلها وتحجيم آثارها 3. المبحث الثاني. مفهوم النجاح المالي وأهميته ومتطلباته The Concept Of مفهوم النجاح المالي: 1.3 Financial Success يعني النجاح في اللغة العربية طبقاً لقاموس مجمع اللغات (السابق،941:1985) بلوغ النتيجة المطلوية . أما في اللغة الانجليزية وطبقاً لقاموس (Webster's, 1974:1163) يعني Hitt, النجاح الوصول إلى ما هو مفضل والوصول إلى التفوق. ويرى Hayes\& ) (Roger, 2005:1) و (2001:101 Pisano, 1996:12-20 ) إن النظر إلى نجاح المنظمة المالية من خلال الاداء المالي، والكفاءة التشغيلية، والانتاجية أو تحقيق ريح أو عائد مستهدف أو إجراء بعض برامج التحسين في إطار الجودة

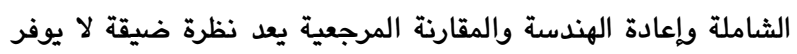
النجاح طويل الأمد في الاسواق التنافسية لأن جميعها يمكن تقليدها او استنساخها بسهولة. ويقصد بالنجاح المالي عدم تعرض المنظمة المالية لخسائر متتالية، وإنما وجود أرباح متتالية، بالإضافة إلى قدرة المنظمة على تسديد ديونها المستحقة، ودفع أرباح أسهمها العادية أو الممتازة، وهو ما

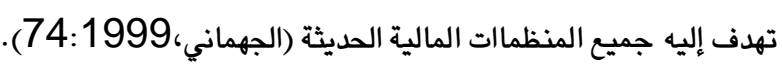
ويشير (261-260 : 2001) بأن نجاح المنظمة هو قدرة إدارتها في الحصول على المعرفة والخبرات والافكار، والتحليل الناجع والدقيق لخبرات المنظمات المالية المناظرة، ولايتحقق إلا بإدارة ناجحة

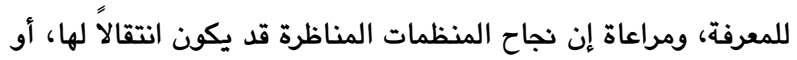

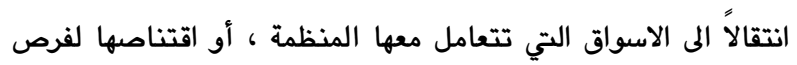

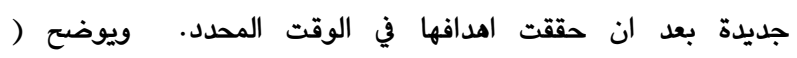
دمام،142:2007) بأن جميع المفاهيم التي وردت في أدبيات الباحثين مثل النجاح التنافسي، والنجاح الاستراتيجي، والنجاح الطويل الأمد، والنجاح التشغيلي، والنجاح المالي تصب مضامينها في مفهوم النجاح المنظمي بوصفه مفهوما شاملاً أما الاختلاف في المسميات فيعود إلى الاختلاف في المداخل وفي النظر إلى النجاح من منظور داخلي

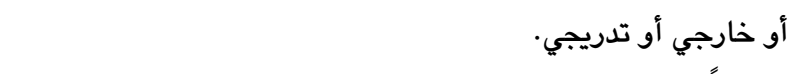
اعتماداً على ماتقدم يمكن تقديم التعريف الاجرائي لمفهوم النجاح المالي بأنه " قدرة المنظمة المالية على تعظيم الريح وذلك من خلال استخدام عدة عناصر ومتطلبات بكفاءة ودمج هذه العناصر والمتطلبات بفاعلية لإنتاج قيمة للزبائن، وهذا يؤدي إلى كفاءة مالية جيدة وتنافس أفضل للمنظمة المالية ويظهر ذلك من خلال تطور
فالتسعير هو وضع أسعار مناسبة تكفي لتغطية التكاليف والحصول على الأرباح من جهة، وأجتذاب الزبائن من جهة أخرى والتسعير الأمثل ليس طريقة لتفطية تكاليف وإحداث غطاء إيجابي فحسب بل إنه إستراتيجية كبيرة يجب أن تأخذ بالاعتبار كل الأهداف التسويقية خلال عملية التسويق (البكري، 56:2005).

على ضوء ذلك فان نجاح المصرف يعتمد على تحديد أسعار خدماته المصرفية بالشكل الذي يتم خلق التوانن بين قيمة الخدمة وما يتوقعه

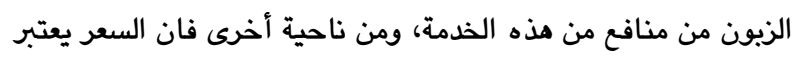

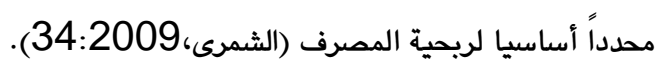
أن الإبداع في التسعير يتمثل في مجموعة أنشطة فرعية تختص بوظيفة التسعير وتتمثل هذه الأنثطة في الإبداع في عملية التوانن بين التسعير

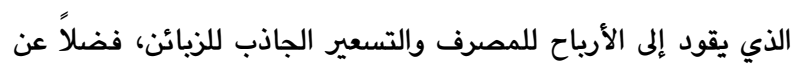
الإبداع في توقيت التسعير في ضوء ظروف البلد والزبائن وحجم الخدمة

المصرفية المقدمة وآلية و استراتيجية التسعير ومرونته.

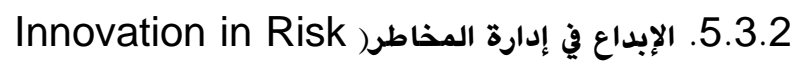
Management وجهات نظر الباحثين المختلفة حول هذا المفهوم فقد تم تعريف توجد تعريفات المخاطرة في قاموس Webster بأنها: إمكانية التعرض إلى الخسارة أو الضرر أو المجازفة، ومن هنا فإن المخاطرة تتضمن احتمالية حصول

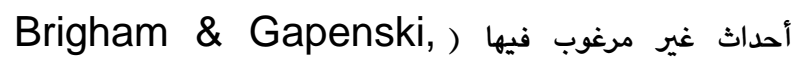
2005:145) وفي مجال الإدارة المالية تعني المخاطرة: الاختلاف في التدفقات النقدية

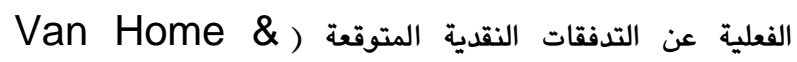
Wachowice, 1995:45). أما في مجال العمل المصرفي فتعني المخاطرة كما عرفها (Keegan,2004:9) بأنها احتمالية تعرض المصرف إلى خسائر غير متوقعة وغير مخطط لها، أو تذبذب العائد المتوقع على استثمار معين، ينتج عنه آثار سلبية لها قدر من التأثير على تحقيق أهداف المصرف المرجوة وتنفيذ استراتيجياته بنجاح. ويرى (Peter,2003:2-3) إن الهدف من إدارة المخاطرة في المنظمات المالية هو تفادي أكبر مخاطرة قد تواجه أي منظمة مالية وهي الإفلاس و تكاليفه المباشرة وغير المباشرة التي تكون في معظمها كبيرة ومعلومة، فالنظرة إلى الإفلاس مستقبلاً كإمكانية غير عادية بالنسبة للمنظمة تؤدي لإعادة الهيكلة أو الإغلاق. ويرى الباحثان بأن أدارة المخاطرة هي عملية تحديد وقياس ومراقبة لإدالة

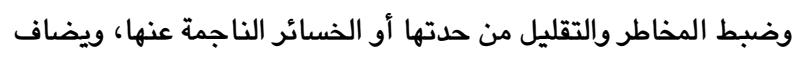
إلى ذلك فن التعامل مع المخاطر وحسن إدارتها بما يضمن تجنيب المصرف التعرض للخسائر الناجمة عن أثكال المخاطر المختلفة التي يواجهها المصرف أثناء قيامه ممارسة نشاطه. . وأن الإبداع في إدارة المخاطر يتمثل في التخطيط للمخاطر من خلال أستخدام أدوات مناسبة لتحديد درجة التأكد وعدم التأكد فضلًا عن تنظيم وتبويب هذه فئ 
تتمثل في: الموارد المالية ، وتكنولوجيا المعلومات، والموارد البشرية ، والقيادة ، والتخطيط المالي ، واستراتيجية التسويق، والوصول إلى

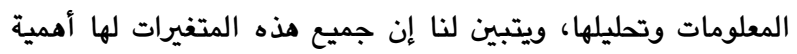
حيوية في نجاح المنظمات المالية والتجارية. كما أن العديد من الأبحاث والدراسات تدعم هذه المتغيرات في نجاح المنظمات المالية ونجاح الأعمال التجارية لذلك سوف نختار هذه المتطلبات موضوعاً للدراسة

$$
\text { الحالية وفيما يلي توضيح متطلبات النجاح المالي : }
$$
1.3.3.الموارد البشرية (The Human Resources): يركز الباحثون في مدخل الموارد البشرية على اهمية سعي المنظمات لتطوير الافراد لكي يحققوا مستويات أعلى من الكفاءة والإنجاز وتصبح المؤسسات بالنسبة لهم كيانات سانده لا كيانات ضابطة وحاكمة فالفلسفة الاساس لهذا المدخل تقوم على أفتراض ان العاملين الافضل ينجزن أعمالاً أفضل لذا حاول الكثير من الباحثين التنظيمين السلوكين أمثال (Roliker) و) و) (Douglas Mc Gregor) جاهدين جعل المنظمات مكان عمل يزخر بممارسات بشرية أكثر مودة

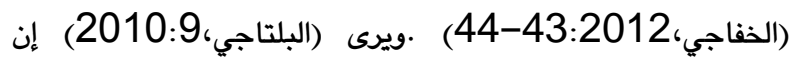

الموارد البشرية تعد من أهم مقومات نجاح الصناعة المصرفية. ويشير (Nickels, et al,2003:328) الى أن إدارة الموارد البشرية هي عملية تقييم الحاجة من الموارد الانسانية ثم إيجاد الافراد المطابقين لتلك الحاجات والحصول على افضل عمل من كل مستخدم من خلال تقديم الحوافز و بيئة العمل الصحيحتين ويما يؤدي إلى تحقيق

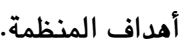
أما (Holden et al,2004:3) فيعتبر أنها توحيد لمجموعة من افن الممارسات مثل التعبئة والتدريب وإدارة العملية والدافعية والقيادة والتقييم والاتصالات بهدف قيادة التحسينات في نوعية قوة عمل المؤسسة بأعتبار أن توحيد ممارسات الموارد البشرية يؤدي إلى نجاح تلك المنظمات. ويعد الاثخاص في جميع المستويات هم أساس باس المنظمة والسماح لهم بالمشاركة الكاملة تمكنهم من إظهار قدراتهم

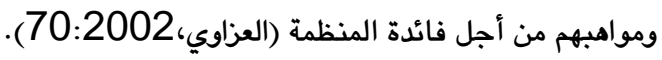
ويشير (Kock,2003:51) أن من المفيد تقييم انظمة ممارسات الموارد البشرية بدلاً من التركيز على الممارسات الفردية والمنطق وراء هذا الافتراض هو ان اداء المنظمة يتعز من خلال أنظمة الممارسات التي تدعم بعضها البعض ويمتلك تاثير الدعم المتبادل على مساهمات المستخدمين باداء المنظمة ففاعلية برامج التدريب الشامل ريما تتعزن عندما تتوحد مع مناهج تقييم اداء المستخدمين.

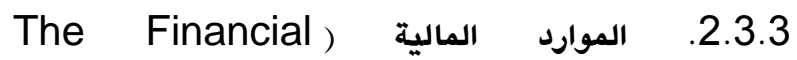
Resources): يقصد بها كيفية الحصول على الأموال اللازمة لأنجاز أعمال المنظمة والتخطيط لكيفية استعمال مذه الأموال ، وهل أن هذه الأموال التي حصلت عليها المنظمة تأتي من بيع السلع والخدمات ، أو الاستثمارات التي تقوم بها ، أو من الاقتراض من
العائدات والاحتفاظ بأكبر قدر من الزبائن والحصة السوقية للمنظمة من بين المنظمات المالية المنافسة". 2.3. أهمية النجاح المالي: The Importance Of Financial Success للنجاح المالي أهمية كبيرة في المنظمات المالية والاقتصاد الوطني أيضاة، ويتبين ذلك من خلال مايأتي: أ. للنجاح المالي أهمية في الرفاه المالي والاجتماعي، ومن المعلوم إن النجاح المالي في أحد مرتكزاته هو المعرفة المالية ويالتالي فأن تحقيق نجاح مالي يعني وجود معرفة مالية فضلاً عن وجود إبداع في السياسات والممارسسات المالية والذي أدى إلى تدقيق في النجاح المالي .(Weiss \& Sherraden ,2014:1) ب. يعد النجاح المالي نظام الإنذار المبكر للتنبؤ بالتعثر المالي حيث يوفر معلومات مستقلة وحقيقية للمنظمة والمدير المالي، والذي يسامم كثيراً في عملية إتخاذ القرار في العلاقات التجارية، حيث إن التعثر المالي يمكن أن يوصل إلى الفشل المالي والذي، وفي حالة عدم معرفة أسباب التعثر المالي فإن أول الخاسرين هم المساهمين في المنظمة ويلي ذلك الموظفين العاملين في المنظمة ويقود ذلك إلى فقدان وظائفهم ويؤدي إلى

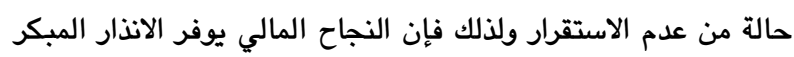

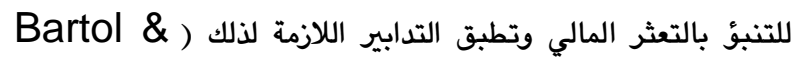
(Nartin, 1991:223-224

ت. للنجاح المالي أهمية في تحديد موية المنظمة وتوجهاتها وسياسات وقواعد العمل للتنظيم الإداري ومن ثم تحديد مقومات ومتطلبات الاستقرار ونمو المنظمات ، كما تحدد طبيعة المنتجات والخدمات التي

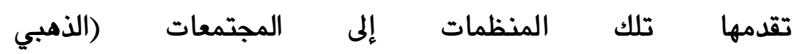
والطائي، 137:2001).

ث. ويضيف الباحثان بأن النجاح المالي يوفر السيطرة الكاملة على إدارة الأموال والقدرة على توفير الخدمات والمعلومات المالية المتنوعة ويالتالي يحقيق الراحة النفسية لدى الأفراد ، فالنجاح المالي لايتطلب أموالاً طائلة لتكون المنظمة المالية ناجحة فحسب بل يتطلب السيطرة الكاملة على إدارة تلك الأموال ومساعدة الآخرين عن طريق تقديم الخدمات المالية الجديدة لهم. The Requirements 3.3. متطلبات النجاح المالي: of Financial Success

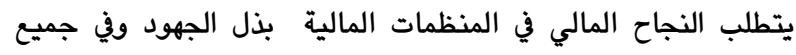
المجالات التي تؤدي إلى النجاح المالي وخاصة في المنافسة الكبيرة التي

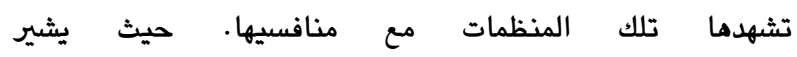
(Vilkinas,2011:8) القيادة الفعالة، وموقع المنظمة المالية، والعوامل اللازمة لإنشاء إناء المنظمة، ومدى توفر هذه العوامل. ويرى(Jasra,et.al.,2011:277) أن متطلبات النجاح المالي 
المرؤوسين ودفعهم نحو إنجاز المهام ورفع الروح المعنوية لديهم وتعزيز قدراتهم وثقتهم بإمكانية مواجهة تلك الظروف وجعلهم ييذلون جهوداً

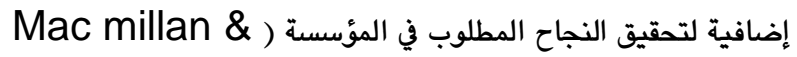
(Tampoe,2000:201 القيادة الجيدة والناجحة تعني التحدي للوضع الراهن، والقيادة ضرورية لمواجهة التحديات الجديدة. وقد أثبتت العديد من الدراسات التطبيقية على أهمية ودود ونمط القيادة للمنظمة من حيث تأثيرها الواسع في العديد من المتغيرات التنظيمية مثل الأداء التنظيمي، والالتزام التنظيمي، الرضا الوظيفي، الإبداع، تخفيض حالات الصراع وتقليل

معدلات دوران أو غياب العمال (Krishnan,2005:16). 4.3.3. التخطيط المالي (Financial Planning): التخطيط من الوظائف المهمة في المنظمات المالية والتي يقع على عاتق القيادة وجوب النهوض به كوظيفة أساسية تختص بها الإدارة العليا، ولا تنتهي هذه الوظيفة إلا بتحقيق الهدف من خلال نشاطات الإدارة التي تعمل على تنفيذ الخطة. ويقصد بالتخطيط " وضع مجموعة من الافتراضات حول الوضع في تئيد الخهل المستقبل أو هو عمل ذهني يعتمد على التفكير العميق والرؤية الصائبة في الحاضر لمواجهة المستقبل" (النمر وآخرون،

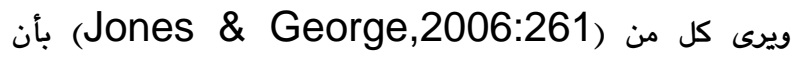
التخطيط هي العملية التي يستعملها القادة الناجحون لتحديد واختيار أهداف وطرق عمل معينة للمنظمة ، وتضع الخطة المنظمية التي تنتج عن عملية التخطيط تفاصيل أهداف المؤسسة وترثيد المدراء إلى كيفية تحقيق هذه الأهداف . أما التخطيط المالي فيعرفه (كراجة، 170:1991) بأنه " نوع من هن هن أنواع التخطيط الذي يهتم بكيفية الحصول على الأموال اللازمة للمشروع من مصادرها المختلفة بأقل التكاليف وأفضل الشروط كما يهتم بكيفية استثمار هذه الأموال بحيث تحقق أفضل و أعلى العوائد للمنظمة ويأقل الأخطار وهو علم له قواعد وأصول ويحتاج إلى خبرة في التطبيق و القدرة على التنبؤ وتحليل الماضي والاعداد للمستقبل". ويعرفه (Pauntu,2010:3) بأنه عملية التأكد وإتخاذ القرار بأفضل وسيلة لجعل أموال المنظمة تعمل لصالحها، ويتم من خلال القيام بالعمل الذي يريد المنظمة إنجازما وكيفيتها والإدراك لأية مشاكل قد تواجهها. ويرى (Emery,et. al.,2007:704) إن التخطيط المالي هو تو عملية تقييم آثار قرارات التمويل والاستثمار البديلة بما هو متوقع في الخطة المالية، ثم مقارنة النتائج المستخرجة مع مذه الخطة. ويوضح كل من (النعيمي والتميمي،169:2008) بأن التخطيط المالي هونشاط متواصل ومستمر ، ويؤثر إلى نمو كل من المؤسسة في ادائها واستثماراتها واحتياجاتها للأموال خلال مدة زمنية محددة.
المنظمات المالية الاخرى (المركهي، 29:2008). ويشير (Thurik,2007:71) المالي خاصة في المنظمات المالية الصغيرة والمتوسطة، فهذه المنظمات تجد صعوية في الحصول على مصادر التمويل والتي تكون

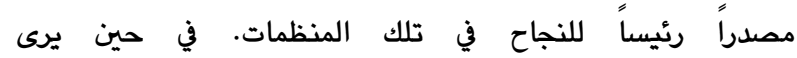
(Pitman,2008:253) نجاح المنظمات المالية الصغيرة والمتوسطة وذلك عن طريق الإستفادة من كسب المال من طرف ثالث وتعتبر أفضل فرصة لنجاحها . وتكمن أهمية الموارد المالية في إمكانية التعبير من خلاله عن مجموعة من القضايا الاقتصادية للأحداث والعمليات التي تقوم بها الوحدة، وتشمل المؤشرات المالية التي تعبر عن صافي أرباح التشغيل، ومعدل العائد على رأس المال المستثمر، والنمو في المبيعات والتدفق النقدي، و هناك إستراتيجيتين يمكن للوحدة إتباعهما لزيادة القيمة الاقتصادية في مجال الأداء المالي هما استراتيجية نمو الإيرادات وتحسين الإنتاجية (السريتي، 196:2013).

ويرى الباحثان ضرورة وجود الموارد المالية الضروية لنجاح المنظمة

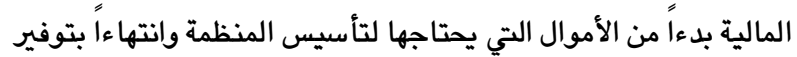
التمويل الدائم لضمان نجاحها. 3.3.3 القيادة(Leadership) : وتعرف القيادة بأنها " عملية التأثير على جماعة في موقف معين ووقت معين وظروف معينة لاسترشاد الأفراد ودفعهم للسعي برغبة لتحقيق أهداف المنظمة مانحة إياهم خبرة

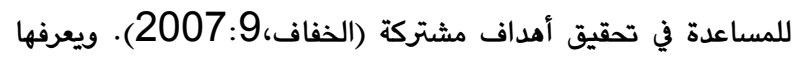
(سلامة،20:2007) بأنها " العمل الذي يؤثر في نشاط المنظمة لتوجيه المجهودات بها في الاتجاه الذي يؤدي الى تحقيق الأهداف

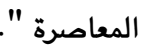
ويعرف (Conger,2002:47) القيادة الناجحة بأنها " القيادة التي تتجاوز تقديم الحوافز مقابل الأداء المرغوب إلى تطوير وتشجيع المرؤوسين فكرياً وأبداعياً وتحويل اهتماماتهم الذاتية لتكون جزءاً

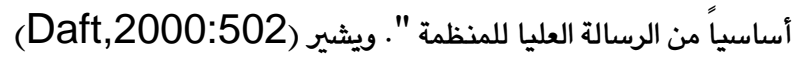
إلى أنه لا يمكن نجاح الأعمال دون توفر القيادة الفعالة، وإن التطور قي مفهوم القيادة سيستمر مع تغير حاجات المنظمة . وتتميز القيادة الناجحة في قدرتها على التأثير الإيجابي في المرؤوسين وكسب رضاهم

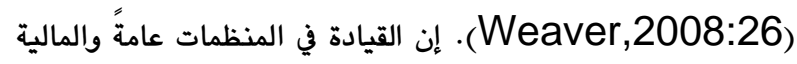
خاصة هي بمثابة الرأس من الجسد للإدارة ومن أجل ذلك تمثل القيادة

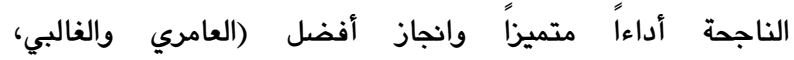
456:2008

ولقد أشار العديد من الباحثين إلى أهمية ودود القائد في نجاح وتدقيق اهداف المنظمة ويما ان عملية التغيير تعد وظيفة تنظيمية حيوية تحتم على جميع المنظمات ان تتغير ويشكل منتظم لكي تتمكن من مواكبة التغيرات والتطورات المستمرة ،حيث يقوم القائد الناجح بتحفيز والهام 
خلال العمل بها وكسب الزبائن الجدد ، ومعظم الدراسات والبحوث تركز غلى أن التكنولوجيا لها دور مهم في نجاح المنظمات المالية والتجارية. ويشير (Butler,2008:103) إن معظم الحكومات في العالم تركز

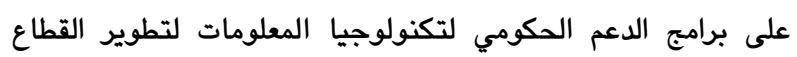

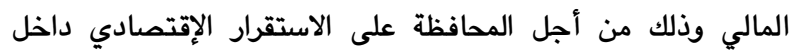

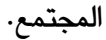

Access to ( 7.3.3 الوصول إلى المعلومات والتحليل Information and Analysis نشاطات جمع المعلومات ونشرها عبر المنظمة المالية والسرعة التي تجمع فيها تلك المعلومات وكيفية إستعمالها ، وأستعمال التحليل

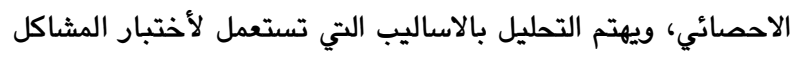
وإستعمال أدوات إحصائية وإستعمال تحليل الجودة والعملية وإنفتاح Shafer \& Meredith, ) المنظمة أمام مقترحات التحسين التعات السعائ .(1998: 92

وهي بذلك تعني إدارة البيانات والمعلومات المالية والطرق المستخدمة

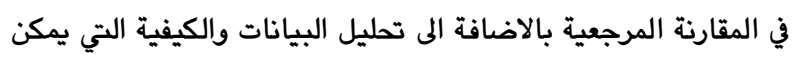
بموجبها إيصال البيانات الى العاملين داخل المؤسسة (العلي، (519:2000).

ويتوقف نجاح المنظمات المالية على قدرة من يجري تمكينهم في الوصول إلى المعلومات المناسبة بالسرعة المطلوبة والدقة الملائمة وفي

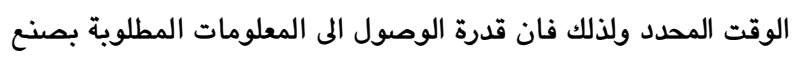
القرارات المبنية على المعلومات المسبقة يتطلب توافر نظم اتصالات فاعلة تحقق ذلك (الملوك،67:2002). كما إن عملية إتخاذ القرارات الرشيدة والفاعلة ينبغي أن تكون مستندة على تحليل البيانات والمعلومات للحصول على الحقائق اللازمة لإتخاذ القرارات بعيداً عن الدس والتخمين أو الخبرة (الفضل والطائي، (292:2004

وتشمل المعلومات والتحليل المقارنة المرجعية والتي تتضمن إختيار مقياس للمنتجات أو الذدمات أو الكلف أو الممارسات التي تمثل أفضل

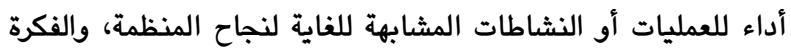

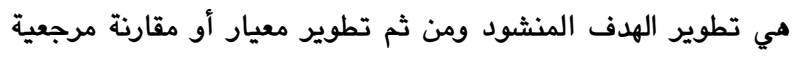
يقارن بها نجاح المنظمة (Heizer \& Render,) 2004:195. وتتألف المقارنة المرجعية من أربع خطوات رئيسة

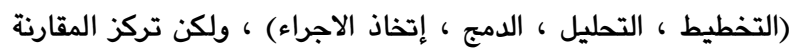

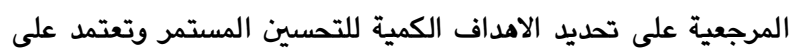
المقارنة مع المنافسين المباشرين وتطبق كل أشكال المقارنة المرجعية بشكل أفضل في المواقف التي يكون فيها البرنامج بعيد الامد للتحسين Krajewski \& Ritzman,1999) المستمر مطلوياً
5.3.3. استراتيجية التسويق (Marketing Strategy): يقصد باستراتيجية التسويق بأنه تقييم مجمل الاستراتيجيات الخاصة بوظيفة التسويق والمتعلقة بعناصر المزيج التسويقي، والتي تشمل المنتج ، والتوزيع ، والترويج والتسعير ، كما تتضمن عملية تقييم نتائج السوق والزبائن، ويساعد الادراة الاستراتيجية في التسويق على توجيه جهودما بهذا الشأن حالياً ومستقبلاً والذي يعزز الموقف التنافسي للمنظمة المالية (Walker,et.al., 1999:164) ويعرفها (الخضيري،306:1999) بأنها "الرؤية الممتدة بالغة الطموح وشديدة الاتساع والتي في إطارما وضوئها تتحدد أنواع القرارات التي تتخذها قمة الجهاز الإداري في المصرف، والتي تتعلق بالمصرف كمنظمة كلية أي تتعلق بمصير ومستقبل ذلك المصرف وتفاعله بين الذات وبين البيئة المحيطة به" ويرى كل من (Verhees \& Meulenberg,2009:27) أن تطوير استراتيجية التسويق هو أمر حيوي للحفاظ الدائم على منى

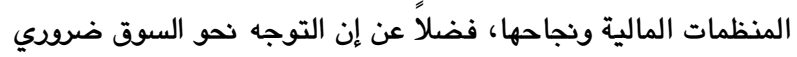
ايضاً لتطوير الأعمال التجارية ويخلق السلوك الضروري لإنشاء قيمة إنها للزبائن ليكونا مرتبطين مع أداء تلك المنظمات، ويشكل أكثر تحديداً لوحظ أن التوجه نحو السوق مثمر في اختيار منتجات جديدة والتي تكون متجانسة مع المنتجات الاخرى في السوق.

6.3.3. تكنولوجيا المعلومات Technological Information التكنولوجيا المتطورة من أجهزة الحاسوب وملحقاته والبرمجيات والشبكات والاتصالات وقواعد البيانات والإجراءات والإفراد التي تستخدم في الاستحواذ على البيانات والمعلومات وتنظيمها ونقلها وخزنها ومعالجتها ونشرها ومشاركتها داخل المنظمة وخارجها مع إمكانية استرجاعها وتحويلها من أجل تحسين موارد نظم المعلومات في المنظمة وتطويرها ومشاركتها وصولاً لتحقيق الأهداف بفاعلية. ويرى (127-120) أن تكنولوجيا المعلومات تلعب دورا هاماً في إمكانية الحصول المعلومات المالية والتي تساعد على البدء بالمشاريع الجديدة والمريحة، وتكنولوجيا المعلومات لها علاقة وثيقة بتحسين عمليات الإنتاج، حيث تساهم هذه المنظمات في التنمية الإقتصادية بطرق مختلفة من خلال خلق فرص العمل والإبداع

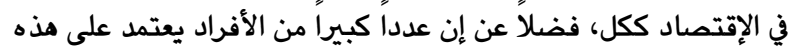
المنظمات بشكل مباشر أو غير مباشر. ويؤكد (Jasra,et,al 2011:277) أن الموارد التكنولوجية هي من أهم عناصر النجاح في أي عمل تجاري وخاصة في المنظمات المالية، فاستخدام التقنيات الحديثة في هذه المنظمات تميل إلى أن تكسب زبائنها أكثر من منافسيها ، وعلى الرغم من أن تكلفة

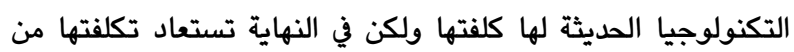


ب. مل هناك علاقة تأثير للإبداع المالي في تحقيق متطلبات النجاح

$$
\text { المالي في المصارف المبحوثة؟ }
$$

2.1.4. أهمية الدراسة : تتجسد أهمية البحث في جانبين مهمين هما: أ. يكتسب البحث أهميته بكونه مساهمة متواضعة لتعميق المعرفة العلمية عبر البحث والتحليل لأهم الآراء التي تناولت مواضيع الدراسة.

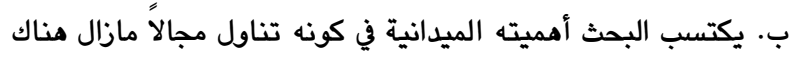
ندرة في الدراسات الميدانية التي أجريت في هذا المجال في بيئة إقليم كوردستان العراق ويحدود اطلاع الباحث ، كما إن الدراسة تكتسب أهميتها الميدانية في أن نتائجها يمكن أن تكون ذات فائدة لإدارة

$$
\text { المصارف المبحوثة. }
$$

3.1.4. أهداف الدراسة: يسعى البحث إلى تقديم إطار فكري لتوضيح مفاهيم الدراسة ذات العلاقة والمتمثلة بكل من أبعاد الإبداع المالي والنجاح المالي باعتباره أحد أهم الأهداف الرئيسة للبحث

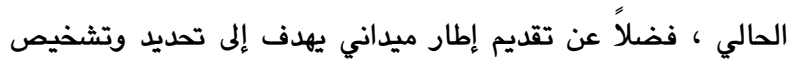
العلاقة والأثر لابعاد الإبداع المالي لتحقيق متطلبات النجاح المالي في تلفي عينة من المصارف الأملية في إقليم كوردستان العراق. 4.1.4. أنموذج البحث ومتغيراته: تتطلب المعالجة المنهجية لمشكلة البحث وفرضياته بناء أنموذج تتكامل مكوناته فيما بينها لتعبر عن العلاقة النظرية بين متغيرات البحث ، والتي تعطي تصورات وإجابات أولية للفرضيات التي افترضها الباحث للإجابة عن الأسئلة المطروحة في مشكلة البحث. ويفترض الأنموذج أن العلاقة بين المتغيرين هي في إتجاه واحد وعليه فأن تحليل العلاقة بين متغيرات الدراسة وحسب الانموذج هو في إتجاه واحد ويوضح الشكل (1) الأنموذج الافتراضي للبحث.
ويوضح (Stevenson,2005:399) على المنظمة المالية التعرف على المنظمات الاخرى التي هي متفوقة في شيء ما ودراسة كيف تفعل ذلك لتتعلم المنظمة الاخرى كيفية تحسين عملياتها، فالمنظمة لا تحتاج أن تكون على نفس المستوى من الاعمال. 4. المبحث الثالث: الإطار المذهجي للبحث

يتطلب التمهيد للإطار الميداني تحديد المنهجية التي يعتمدها الباحث في ضوء تدديد مشكلة البحث وأهدافها وأهميتها وفرضياتها ويناء

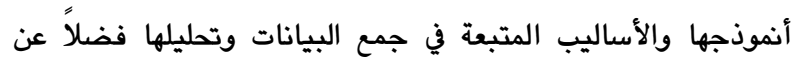
وصف مجتمع الدراسة وماهية حدود الدراسة.

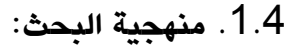

تعد منهجية البحث بمثابة خارطة العمل لاقامة الدراسة الميدانية والوسيلة التي يتم من خلالها تحديد مشكلة الدراسة ووضع انموذجها وفرضياتها ، ورسم مسارات جمع البيانات وتحليلها وذلك وفق الفقرات الآتية:

1.1.4 مشكلة البحث: تشير بعض المؤتمرات وورثات العمل التي اقيمت في إقليم كوردستان العراق منها (مؤتمر المصارف التجارية في أربيل 2008) و( مؤتمر أتحاد الغرف التجارية في إقليم كوردستان عن القطاع المصرفي 2014) و ( ورثة العمل التي أقامها رابطة المصارف الأهلية 2014)، إلى أن أداء المصارف التجارية دون (20) مستوى الطموح وهي بالتالي بحاجة إلى تطبيق بعض المنطلقات

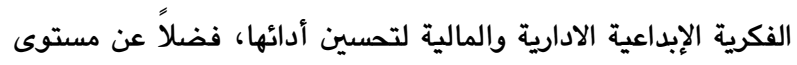
متقدم من العمليات المؤتمتة ذات التقنيات الملائمة مع المناخ المصريي ويناءاً على ماسبق يمكن توضيح مشكلة الدراسة بشكل ملخص من

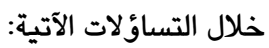
أ. مل هناك علاقة ارتباط بين الإبداع المالي ومتطلبات النجاح المالي

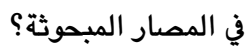




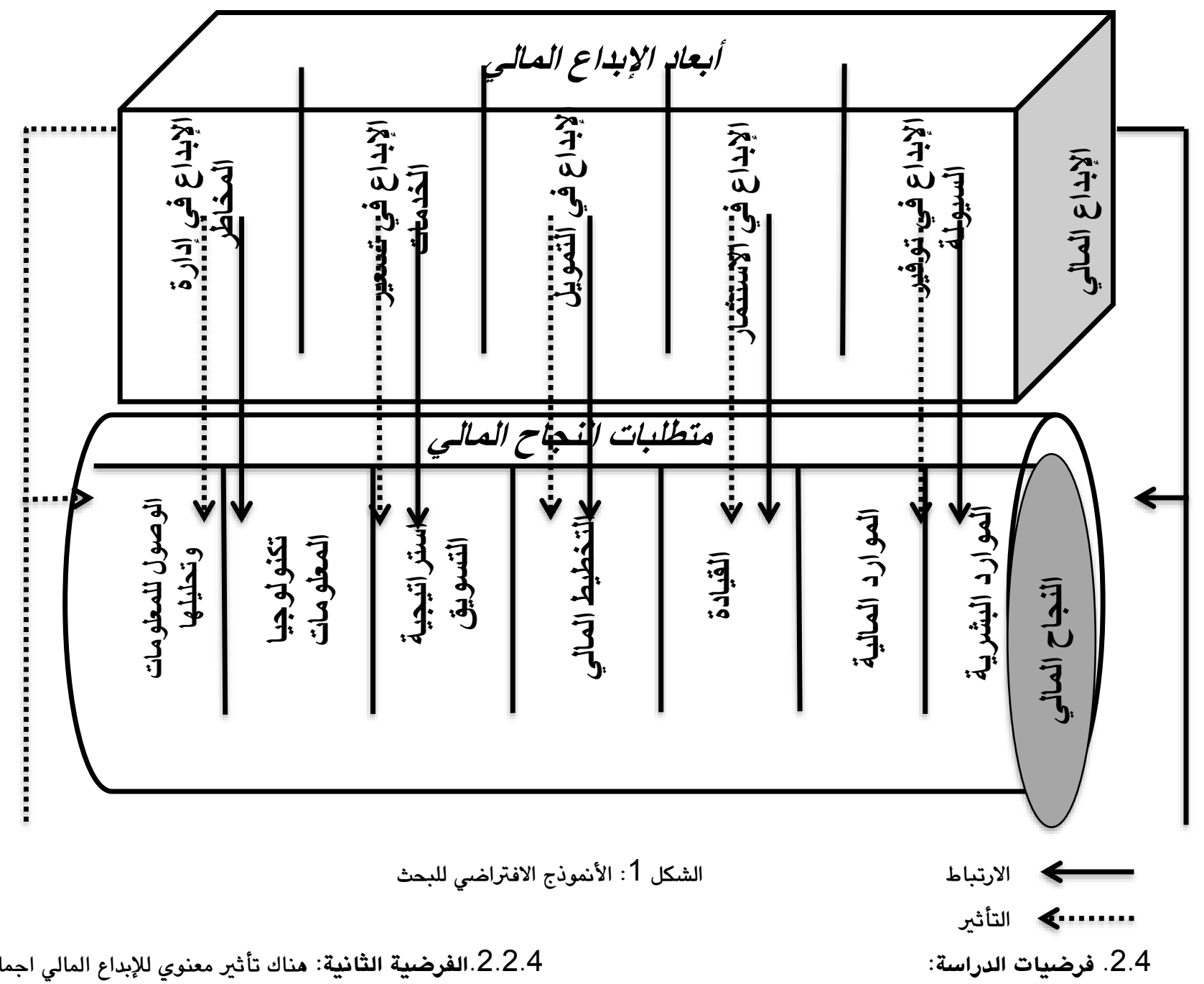

وتفصيلاً في النجاح المالي للمصارف المبحوثة. وتتفرغ منها الفرضيات

الفرعية الآتية:

أ. هناك تأثير معنوي للإبداع في توفر السيولة على النجاح المالي في

المصارف المبحوثة.

ب • مناك تأثير معنوي للإبداع في الاستثمار على النجاح المالي في

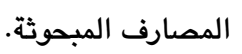

ت. . هناك تأثير معنوي للإبداع في التمويل على النجاح المالي في

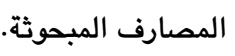

ث. هناك تأثير معنوي للإبداع في تسعير الخدمات المصرفية على

$$
\text { النجاح المالي في المصارف المبحوثة. }
$$

هناك تأثير معنوي للإبداع في إدارة المخاطر على النجاح المالي في

المصارف المبحوثة.

3.2.4.الفرضية الثالثة: هناك تباين في المتغير المعتمد ( النجاح

المالي ) طبقاً للتركيز على المتغير المستقل ( الإبداع المالي ) في

المصارف المبحوثة وعلى مستوى المحافظات الثلاثة.

3.4. أساليب جمع البيانات والمعلومات
واستكمالاً لمتطلبات البحث ، تمت صياغة مجموعة من الفرضيات الرئيسة والفرعية المنبثقة من أنموذج البحث نعرضها على النحو الأتي: 1.2.4.الفرضية الأولى: هناك علاقة ارتباط معنوية بين الإبداع المالي اجمالاً وتقصيلًا والنجاح المالي في المصارف المبحوثة. هناك

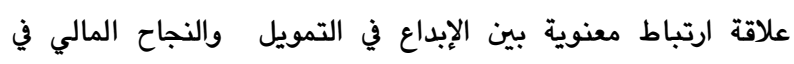
المصارف المبحوثة. وتتفرع منها الفرضيات الفرعية الآتية: أ. مناك علاقة ارتباط معنوية بين الإبداع في توفر السيولة والنجاح

$$
\text { المالي في المصارف المبحوثة. }
$$

ب. . هناك علاقة ارتباط معنوية بين الإبداع في الاستثمار والنجاح المالي

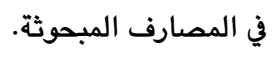

ت . مناك علاقة ارتباط معنوية بين الإبداع في التمويل والنجاح المالي

$$
\text { في المصارف المبحوثة. }
$$

ث. مناك علاقة ارتباط معنوية بين الإبداع في تسعير الذدمات المصرفية والنجاح المالي في المصارف المبحوثة.

ج. مناك علاقة ارتباط معنوية بين الإبداع في إدارة المخاطر والنجاح

$$
\text { المالي في المصارف المبحوثة. }
$$


تكنولوجيا المعلومات وشملت الفقرات (X70 - X74 )، وشمل القسم السابع والأخير من هذا الجزء الفقرات الخاصة بمتطلب الوصول إلى المعلومات وتحليلها وتمثلت بالفقرات ( X80 - X75 ).

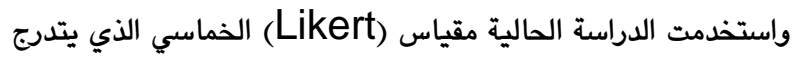

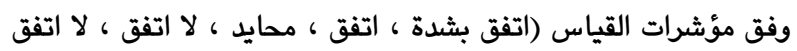

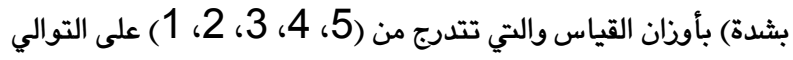

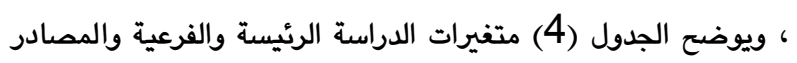

التي اعتمدها الباحث عند تصميم الاستبانة. 4.4. أساليب تحليل بيانات البحث: تم اعتماد البرمجية

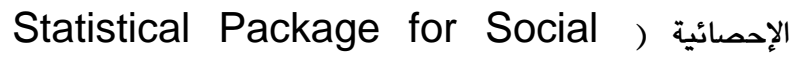
(SPSS V. 19) وبالنسخة (SPiences

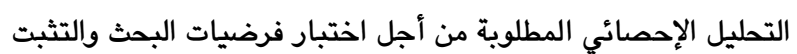
من صحتها و إيجاد العلاقات بين متغيراتها، وذلك من خلال المقاييس الآتية:

1. استخدام معامل الارتباط البسيط لتحديد قوة وطبيعة العلاقة بين المتغير المستقل( أبعاد الإبداع المالي ) والمتغير المعتمد ( متطلبات

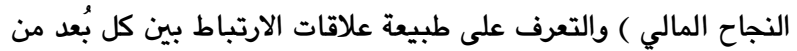
أبعاد الإبداع المالي وبين النجاح المالي.

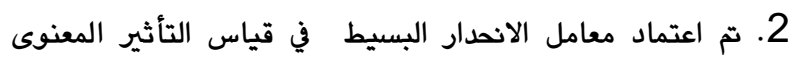
لمتغير الإبداع المالي في متغير النجاح المالي. وكذلك للتوصل إلى العلاقة التأثيرية لكل بُعد من أبعاد الإبداع المالي في النجاح المالي. 3. وتم اعتماد تحليل التباين (ANOVA) باستخدام المؤثر الاحصائي (F) للكشف عن مستويات التباين في المتغير المعتمد (النجاح المالي) طبقاً للتركيز على المتغير المستقل ( الإبداع المالي) في المصارف المبحوثة وعلى مستوى المحافظات الثلاثة.

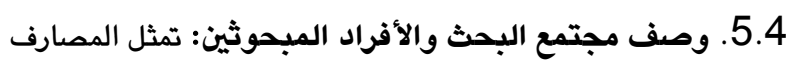
الأملية المتواجدة في إقليم كوردستان العراق والبالغ عددها (75) مصرفاً مجتمع البحث الحالي ، حيث تم انتخاب عينة عشوائية مكونة من (21) مصرف من بين تلك المصارف والتي مثلت نسبة ( .28\%) من مجموع المصارف المتواجدة في إقليم كوردستان العراق، والجدول (1) يبين عدداً من البيانات التعريفية الخاصة بوصف تلك العينة.
من أجل الحصول على البيانات اللازمة لإتمام هذا البحث والوصول إلى النتائج المحددة وتحقيق أهدافه ، فقد تم اعتماد على ما هو متوفر من

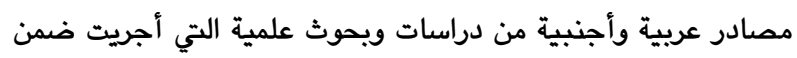
إطار المفاهيم العلمية لهذه الدراسة بجانب عدد من الأطاريح والرسائل الجامعية ذات الصلة بموضوع البحث فضلاً عن عدد من الكتب ، فضلاً عن استخدام شبكة الانترنيت للإطلاع على أحدث ما كتب حول موضوع البحث وذلك بهدف إكمال متطلبات الجانب النظري للبحث. واعتمد الباحثان على الاستبانة للحصول على البيانات الخاصة بالجانب الميداني، تضمن الجزء الاول البيانات الخاصة، فيما ركز الجزء الثاني على العبارات الخاصة بالمتغير المستقل ( الإبداع المالي) وقد خصص

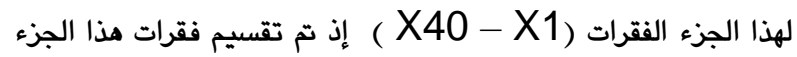

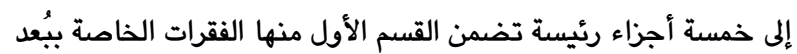
الإبداع في توفير السيولة وشملت الفقرات (X8 - X1 ) أما القسم الثاني فقد تضمن الفقرات الخاصة ببعد الإبداع في الاستثمار وشملت

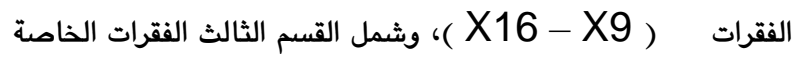
بُبعد الإبداع في التمويل وتمثلت بالفقرات ( X17 - X24 )، أما ل القسم الرابع فقد تمثلت بيُعد الإبداع في تسعير الخدمات المصرفية

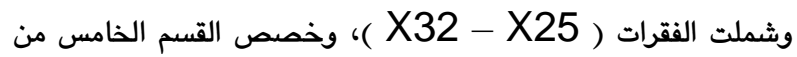
هذا الجزء للفقرات الخاصة بيُعد الإبداع في إدارة المخاطر والتي تمثلت

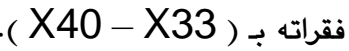
اما الجزء من الاستمارة فقد ركز على المعايير الخاصة بمتطلبات النجاح

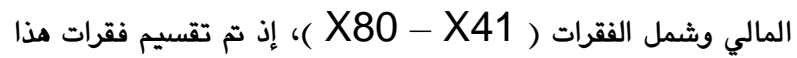
الجزء إلى سبعة أقسام رئيسة تضمن القسم الأول منها الفقرات الخاصة

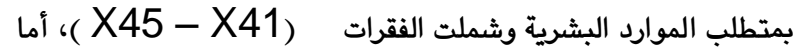
القسم الثاني فقد تضمن الفقرات الخاصة بمتطلب الموارد المالية وشملت الفقرات (X46 - X51 )، وشمل القسم الثالث الفقرات

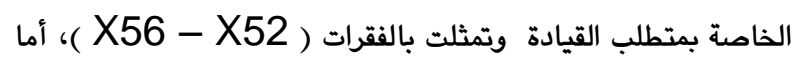
القسم الرابع فقد تمثلت بمتطلب التخطيط المالي وشملت الفقرات( Xم ل

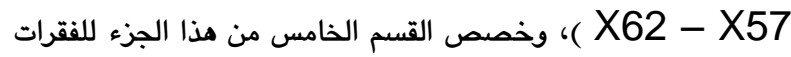

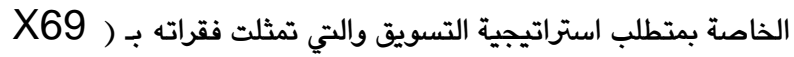
X63 - ) )، أما القسم السادس فقد تضمن الفقرات الخاصة بمتطلب 
الجدول 1 : وصف المصارف عينة البحث

\begin{tabular}{|c|c|c|c|}
\hline عدد العاملين & سنة التأسيس & أسم المصرف & ت \\
\hline 15 & 1992 & مصرف بغداد/ فرع زاخو & 1 \\
\hline 14 & 1993 & مصرف الشرق الاوسط للاستثمار/ فرع زاخو & 2 \\
\hline 16 & 1995 & المصرف الأهلي العراق / أربيل & 3 \\
\hline 12 & 1999 & مصرف سومر التجاري / أربيل & 4 \\
\hline 15 & 2001 & مصرف موصل للتنمية والاستثمار / دهوك & 5 \\
\hline 45 & 2005 & مصرف الأقليم التجاري RT/ دهوك & 6 \\
\hline 120 & 2005 & مصرف الإقليم التجاري RT / أربيل & 7 \\
\hline 185 & 2005 & مصرف كوردستان الدولي / أربيل & 8 \\
\hline 80 & 2005 & مصرف الشمال للاستثمار والتمويل / السليمانية & 9 \\
\hline 25 & 2006 & مصرف البلاد الاسلامي / زاخو & 10 \\
\hline 20 & 2006 & مصرف انتركونتينتتال اللبناني / أربيل & 11 \\
\hline 60 & 2006 & مصرف دجلة والفرات للاستثمار والتنمية/ السليمانية & 12 \\
\hline 90 & 2006 & مصرف كودرستان الدولي / دهوك & 13 \\
\hline 17 & 2007 & مصرف مصرف آشور التجاري/ أربيل & 14 \\
\hline 18 & 2007 & مصرف منصور للاستثمار/ السليمانية & 15 \\
\hline 25 & 2008 & مصرف الشمال للاستثمار/ دهوك & 16 \\
\hline 95 & 2008 & مصرف كوردستان الدولي / السليمانية & 17 \\
\hline 30 & 2008 & مصرف جيهان للاستثمار والتمويل/ السليمانية & 18 \\
\hline 55 & 2009 & مصرف أربيل للاستثمار والتمويل/ أربيل & 19 \\
\hline 40 & 2009 & مصرف أربيل للاستثمار والتمويل / السليمانية & 20 \\
\hline 12 & 2012 & المصرف المتحد للاستثمار / زاخو & 21 \\
\hline
\end{tabular}

المصدر: من إعداد الباحثان. ملاحظة: تم ترتيب المصارف حسب سنة التأسيس

الفرضية الثانية التي تشيى إلى وجود علاقات الارتباط بين كل بُعد من أبعاد الإبداع المالي والنجاح المالي. ويشير الجدول (2) إلى معاملات الارتباط بين المتغير المستقل (الإبداع المالي) والمتغير المعتمد (النجاح المالي)، إذ تشير معطيات الجدول المذكور إلى وجود علاقة ارتباط إحصائية ذات دلالة معنوية بين أبعاد الإبداع المالي والنجاح المالي، حيث بلغ معامل الارتباط (0.778) وهي قيمة معنوية عند مستوى (0.01) ويذلك فإن العلاقة طردية بنسبة حوالي (77.8\%) بين المتغيرين أي كلما أهتمت المصارف المبحوثة بأبعاد الإبداع المالي كلما أدى ذلك إلى النجاح المالي بالنسبة المذكورة ويذلك فقد تحققت الفرضية الرئيسة الاولى التي تنص على أن هناك علاقة ارتباط معنوية بين أبعاد الإبداع المالي والنجاح المالي

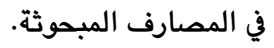

- - كما ويشير الجدول (2) إلى أن هناك علاقات ارتباط بين كل بُعد من أبعاد الإبداع المالي والنجاح المالي ، واتضح من الجدول المذكور أن أقوى علاقة ارتباط معنوية كانت بين بُعد الإبداع في الاستثمار ومتطلبات النجاح المالي ، إذ بلغت قيمة الارتباط (0.689) وهي قيمة معنوية عند مستوى (0.01) ويذلك فإن العلاقة طردية بنسبة

\section{5. المبحث الرابع: الإطار الميداني للبحث}

لغرض التحقق من مدى صحة الافتراضات و تحليل العلاقات بين متغيرات البحث وذلك استخدامنا عدد من الأدوات والأساليب الاحصائية التي اختيرت لإجراء التحليل على البيانات الميدانية للبحث ويحسب

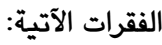
1.5. تحليل علاقات الارتباط بين متغيرات البحث: استكمالاً لمنهجية البحث فقد تم إجراء اختبار لعلاقات الارتباط بين متغيرات البحث، للتأكد من وجود علاقة ارتباط معنوية بين أبعاد الإبداع المالي ومتطلبات النجاح المالي على المستوى الكلي والجزئي عبر

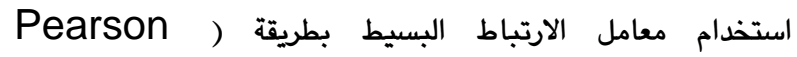
Correlation أ. علاقة الارتباط بين الإبداع المالي والنجاح المالي اجمالا وتفصيلاً على المستوى الكلي للمصارف عينة البحث: تركز هذه الفقرة على اختبار الفرضية الرئيسية الثانية، التي تشير إلى وجود علاقة ارتباط معنوية بين أبعاد الإبداع المالي والنجاح المالي في المصارف عينة الدراسة، واختبار الفرضيات الفرعية المنبثقة من 
هناك علاقة ارتباط معنوية بين الإبداع في تسعير الخدمات المصرفية والنجاح المالي في المصارف المبحوثة. - - أما في المرتبة الرابعة فقد جاءت علاقة الارتباط بين بُعد الإبداع في إدارة المخاطر والنجاح المالي في الجدول (2)، إذ بلغت قيمة الارتباط (0.546) وهي قيمة معنوية عند مستوى (0.01) ويذلك فأن العلاقة طردية بنسبة حوالي (.54.6) أي أنه كلما كانت لدى المصارف جهة مختصة لإدارة المخاطر وتعويم أسعار الفائدة على التسهيلات الائتمانية لتلافي مخاطر أسعار الفائدة واقتراح أساليب جديدة لأداء العمل رغم علمها بالمخاطر المترتبة على ذلك واعتبار المخاطر فرص تحقق من

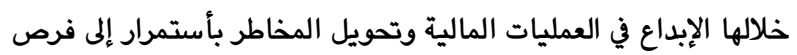
للنجاح كلما أدى إلى النجاح المالي فيها، ويهذا تقبل الفرضية الفرعية الخامسة والمنبثة من الفرضية الرئيسة الاولى والتي تنص على على أن هناك علاقة ارتباط معنوية بين الإبداع في إدارة المخاطر والنجاح

$$
\text { المالي في المصارف المبحوثة. }
$$

- مي حين ان المرتبة الأخيرة لعلاقات الارتباط كانت بين بُعد الإبداع في توفير السيولة في الجدول (2)، إذ بلغت قيمة الارتباط (0.477) وهي قيمة معنوية عند مستوى (0.01) ويذلك فأن العلاقة طردية بنسبة حوالي (48\%) أي أنه كلما قامت المصارف بعمل دراسة تحليلية لنسب تطور السيولة وقدرتها على التوانن بين مصادر الأموال واستخداماتها ووجود جهة مختصة لإدارة السيولة فيها والتي أحد تخفيض تكلفة الأموال لدى المصارف وتخفيض أسعار خداماته غير الأئتمانية لاستقطاب ودائع جديدة ويالتالي الحصول على سيولة إضافية وأعتمادما على المعلومات المالية والمحاسبية في إدارة السيولة وكذلك الاعتماد على أساليب مالية متطورة ومبدعة لتخطيط السيولة لديها واستغلال فائض السيولة في أوجه استثمارية اخرى مدرة للعوائد، كلما أدى إلى النجاح المالي فيها، ويهذا تقبل الفرضية الفرعية الأولى لهيه والمنبثقة من الفرضية الرئيسة الاولى والتي تنص على على أن هناك علاقة ارتباط معنوية بين الإبداع في توفير السيولة والنجاح المالي في

المصارف المبحوثة.

ويهذا فقد تحققت الفرضية الرئيسة الاولى وجميع الفرضيات الفرعية

المنبثقة منها.
حوالي (69\%) بين المتغيرين مما يدل على أن المصارف كلما تبنت سياسة تشغيل الأموال والبحث عن أفضل الفرص الاستثمارية وتنويع مجالات استثماراتها قدر المستطاع والحرص على تقدير وقياس المخاطر المتعلقة بالاستثمارات كلما أدى ذلك إلى النجاح المالي فيها، ويهذا تقبل الفرضية الفرعية الثانية والمنبثقة من الفرضية الرئيسة الاولى والتي تنص أن هناك علاقة ارتباط معنوية بين الإبداع في الاستثمار والنجاح المالي للمصارف المبحوثة. - أما ثاني أقوى علاقات الارتباط فكانت بين بُعد الإبداع في التمويل والنجاح المالي في الجدول (2)، إذ بلغت قيمة الارتباط (0.682) وهي قيمة معنوية عند مستوى (0.01) ويذلك فإن العلاقة طردية بنسبة حوالي (\%68.2\%) بين المتغيرين أي أنه كلما قامت المصارف بتحديد إحتياجاتها من الأموال وتحديد مصادر التمويل اللازمة لها واختيار البديل الأفضل من بين مصادر التمويل المتاحة وتوفيرها في مهل الوقت المناسب والتأكد من ملائمة نوع التمويل للاستخدام الموجه إليه والحرص على تسديد ديونها مع أوقات حصولها على الأموال كلما أدى إلى النجاح المالي فيها ، ويهذا تقبل الفرضية الفرعية الثالثة المنبثقة من الفرضية الرئيسة الاولى والتي تنص على على أن هناك علاقة ارتباط معنوية بين الإبداع في التمويل والنجاح المالي في المصارف المبحوثة. - مجاءت في المرتبة الثالثة علاقة الارتباط بين بُعد الإبداع في تسعير الخدمات المصرفية والنجاح المالي في الجدول (2)، إذ بلغت قيمة الارتباط (0.573) وهي قيمة معنوية عند مستوى (0.01) ويذلك فأن العلاقة طردية بنسبة حوالي (.57.3) بين المتغيرين أي أنه كلما أهتمت المصارف بدراسات السوق وتحليلاته والقيام بالمسح السوقي بشكل دوري لمعرفة الأسعار السائدة في السوق وتوفر وحدات متخصصة بالتسعير و دراسة أسعار المنافسين قبل تحديد أسعار خدماتها ودراسة مستوى إقبال الزبائن على الخدمات عند تعديلها وتوزيع التكاليف والإيرادات على مراكز التكلفة وتدخل الادارة العليا في مراحل قليلة ومحددة من تسعير مراحل تسعير الخدمة وتخفيض أسعار الفوائد المقبوضة بمقدار الزيادة في أرباحها غير الائتمانية كلما أدى إلى مراهي النجاح المالي في المصارف المبحوثة ، ويهذا تقبل الفرضية الفرعية الرابعة والمنبثقة من الفرضية الرئيسة الاولى والتي تنص على على أن الجدول (2):علاقات الارتباط بين أبعاد الإبداع المالي والنجاح المالي على المستوى الكلي للمصارف عينة الدراسة

\begin{tabular}{|c|c|c|c|c|c|c|c|}
\hline \multirow[b]{2}{*}{ المؤشر الكلي } & \multicolumn{5}{|c|}{ أبعاد الإبداع المالي } & \multirow{2}{*}{ المتغير المستقل } & \multirow[b]{2}{*}{ المتغير المعتمد } \\
\hline & الإبداع في إدارة & الإبداع في & الإبداع في & الإبداع في & $\begin{array}{c}\text { الإبداع في توفير } \\
\text { السيولة }\end{array}$ & & \\
\hline $0.778^{\star \star}$ & $0.546^{\star \star}$ & $0.573^{\star *}$ & $0.682^{\star \star}$ & $0.689^{\star \star}$ & $0.477^{\star \star}$ & & النجاح المالي \\
\hline
\end{tabular}


ويظهر الجدول (3) إلى وجود أثر معنوي عالي جداً للإبداع المالي

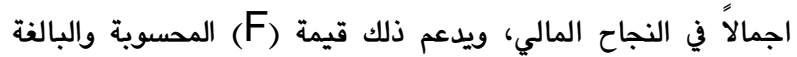

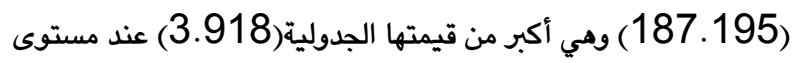

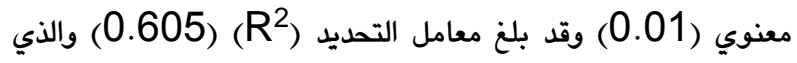
يشير إلى قدرة المتغيرة المستقل في تفسير التأثير الذي يطرأ على التى

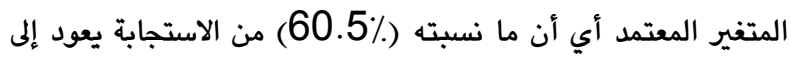

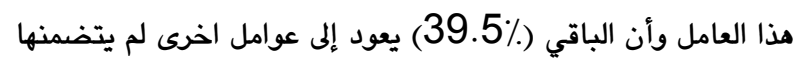

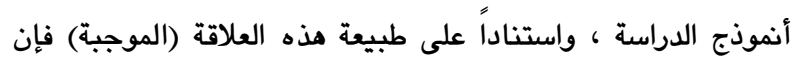

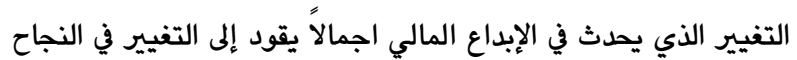

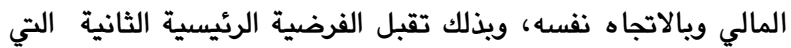

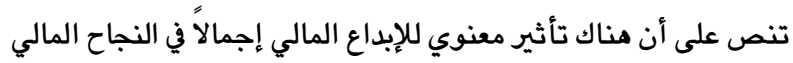

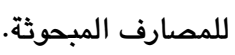

الجدول 3: أثر الإبداع المالي اجمالاً في النجاح المالي على المستوى الكلي للمصارف عينة الدراسة المبحة

\begin{tabular}{|c|c|c|c|c|c|c|}
\hline & & & & & النجاح الما & المتغير المعتمد \\
\hline \multirow[t]{2}{*}{ Sig } & & $F$ & $\mathrm{R}^{2}$ & B1 & B0 & \multirow[b]{2}{*}{ المتغير المستقل } \\
\hline & الجدولية & المحسوية & & & & \\
\hline 0.000 & 3.918 & 187.195 & 0.605 & $\begin{array}{r}0.778 \\
(13.68)^{*}\end{array}$ & 0.987 & الإبداع المالي \\
\hline
\end{tabular}

2.5. تليل علاقات التأثير بين متغيرات الدراسة: يتم في هذا المحور قياس أثر المتغير المستقل في المتغير المعتمد، وما ينبثق عن ذلك من فرضيات فرعية، وذلك باعتماد أسلوب الانحدار

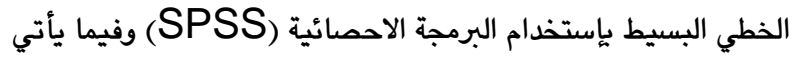
أثر متفيرات الدراسة فضلاً عن تفسير المدلولات الاحصائية وعلى النحو لإنية

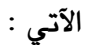

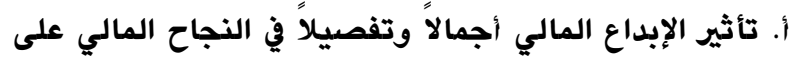
المستوى الكلي للمصارف عينة الدراسة: تتضمن هذه الفقرة اختبار الفرضية الرئيسة الثانية التي تشير إلى وجود التئي

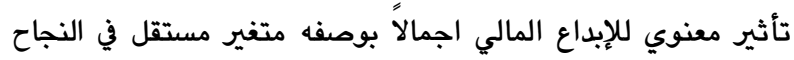
المالي كمتغير معتمد في المصارف المبحوثة في إقليم كوردستان العراق.

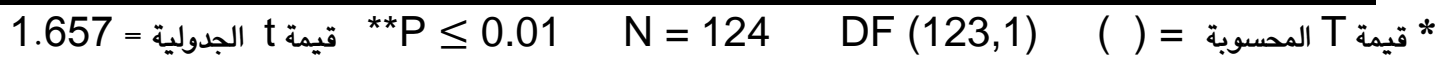

المصدر : من إعداد الباحثان بالاعتماد على مخرجات البرمجية الإحصائية ( ( SPSS ) .

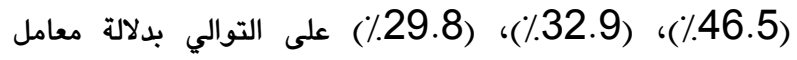

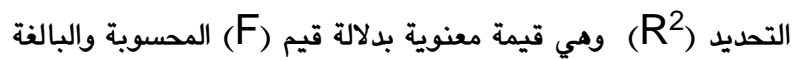

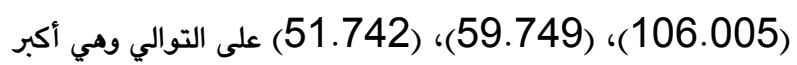

من قيمتها الجدولية البالغة (3.918). وتأسيساً على هذه المعطيات يمكن القول أن بعض النتائية البالفة مثل تبني الإبداع في الاستثمار وسياسة تشغيل الأموال وعدم تجميدها والبحث عن الفرص الاستثمارية وتنويع مجالات الاستثمار والإبداع في التمويل والتسعير يؤدي إلى النجاح المالي في المصارف، بمعنى أن نجاح النياح

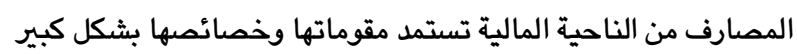

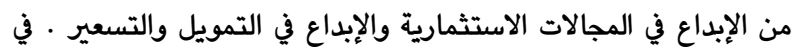
حين أن نتائج الإبداع في توفير السيولة والإبداع في ادارة المخاطر في

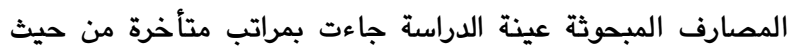

$$
\text { تأثيرما في الإبداع المالي في المصارف المبحوثة. المراسة حاءت بدرات }
$$

ب. تأثير كل بُعد من أبعاد الإبداع المالي في النجاح المالي على المستوى الكلي للمصارف عينة الدراسة:

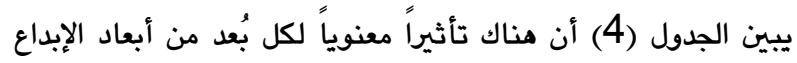

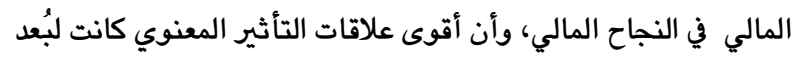

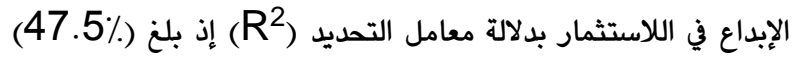

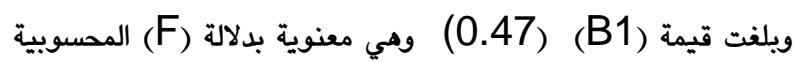
والبالغة (110.533) وهي أكبر من قيمتها الجدولية والبالغة

في حين إن أقل علاقة تأثير معنوي كان لُُعد الإبداع في توفير السيولة

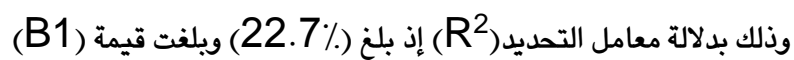

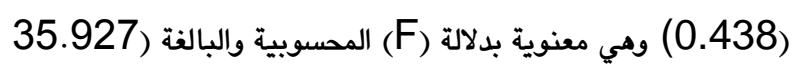

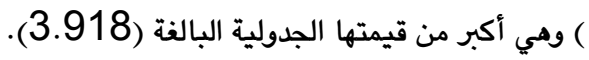

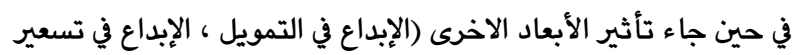
الخدمات المصرفية، الإبداع في إدارة المخاطر) بنسب تأثيرية بلغت 
الجدول 4: أثر كل بُعد من أبعاد الإبداع المالي في النجاح المالي في المصارف عينة الدراسة

\begin{tabular}{|c|c|c|c|c|c|c|}
\hline \multicolumn{6}{|c|}{ النجاح المالي } & \multirow{3}{*}{ المتغير المعتمد } \\
\hline \multirow[t]{2}{*}{ Sig. } & \multicolumn{2}{|c|}{$F$} & \multirow[t]{2}{*}{$\overline{R^{2}}$} & \multirow[t]{2}{*}{ B1 } & \multirow[t]{2}{*}{ B0 } & \\
\hline & الجدولية & المحسوية & & & & \\
\hline \multirow[t]{2}{*}{0.000} & 3.918 & 35.927 & 0.227 & 0.477 & 0.528 & الإبداع في توفير السيولة \\
\hline & & & & $(5.994) *$ & & \\
\hline \multirow[t]{2}{*}{0.000} & 3.918 & 110.533 & 0.475 & 0.689 & 0.645 & الإبداع في الاستثمار \\
\hline & & & & (10.513) & & \\
\hline \multirow[t]{2}{*}{0.000} & 3.918 & 106.005 & 0.465 & 0.682 & 0.733 & الإبداع في التمويل \\
\hline & & & & (10.296)* & & \\
\hline \multirow[t]{2}{*}{0.000} & 3.918 & 59.749 & 0.329 & 0.573 & 0.496 & الإبداع في التسعير \\
\hline & & & & $(7.730) *$ & & \\
\hline \multirow[t]{2}{*}{0.000} & 3.918 & 51.742 & 0.298 & 0.546 & 0.493 & الإبداع في إدارة المخاطر \\
\hline & & & & (7.193)* & & \\
\hline
\end{tabular}

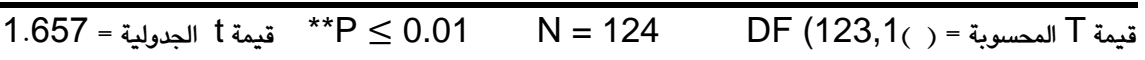

المصدر : من إعداد الباحث بالإعتماد على مخرجات البرمجية الإحصائية ( ) SPSS ).

تباين المصارف في محافظة أربيل في تدقيقها للنجاح المالي وفقاً

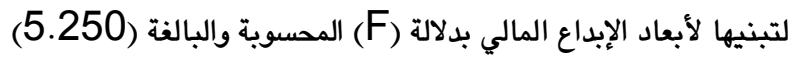

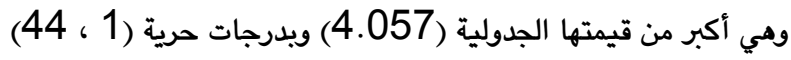
مما يؤكد وجود فروق ذات دلالة احصائية بين مصارف محافظة أربيل تجاه متغير النجاح المالي وفقاً لتبنيها لأبعاد الإبداع المالي بين

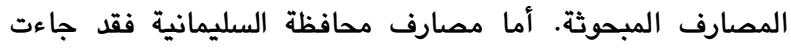

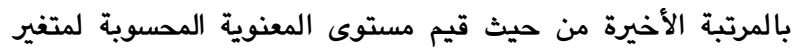

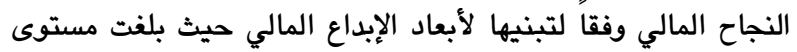
المعنوية المحسوبة (0.238) والتي تزيد عن المستوى الافتراضي (0.05) مما يشير إلى عدم تباين المصارف في محافظة السليمانية في تحقيقها للنجاح المالي وفقاً لتبنيها لأبعاد الإبداع المالي بدلالة (F) تماندان المحسوبة والبالغة (2.085) وهي أقل من قيمتها الجدولية

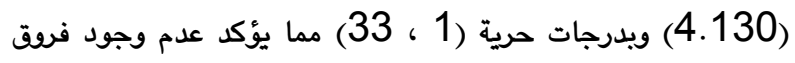
ذات دلالة احصائية بين مصارف محافظة السليمانية تجاه متغير ودات النجاح المالي وفقاً لتبنيها لأبعاد الإبداع المالي بين المصارف

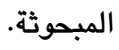
وتأسيسا على المعطيات السابقة يمكن القول بأن فرضية التباين قد

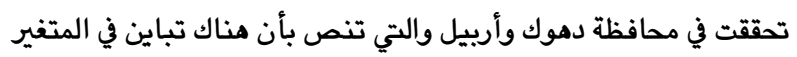
المعتمد (النجاح المالي) طبقاً للتركيز على المتغير المستقل (الإبداع المالي) في المصارف المبحوثة في محافظتي دهوك وأربيل.

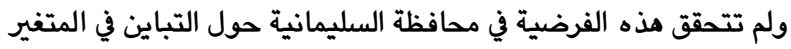
المعتمد (النجاح المالي) طبقاً للتركيز على المتغير المستقل (الإبداع

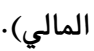

3.5. تحليل علاقات التباين بين متغيرات البحث في المصارف

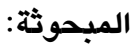

نتناول في هذه الفقرة اختبار فرضية التباين وذلك باستخدام تحليل

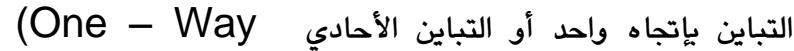
للتعرف على الفرق الاحصائية بين متغيرات الدراسة في الاحي المصارف المبحوثة في المحافظات الثلاثة في إقليم كوردستان العراق، وذلك من خلال المؤشر الاحصائي (F) لكونه الأداة الإحصائية المناسبة للتعرف على الفروقات بين عناصر متغيرات الدراسة، حيث يتم قبول قيمة الخطأ الإحصائي لمعنوية التباين لغاية (0.05) وكما تشير نتائج تحليل التباين الأحادي في الجدول (5) إلى قيم مستوى المعنوية المحسوبة لمتغير النجاح المالي وفقاً لتبنيها لأبعاد الإبداع المالي، وجاءت في المرتبة الأولى مصارف محافظة دهوك حيث قد بلغت مستوى المعنوية المحسوية (0.001) في المصارف المبحوثة في

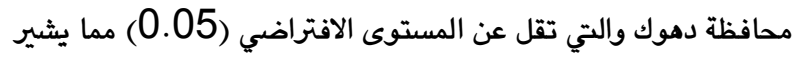
إلى تباين المصارف في محافظة دهوك في تحقيقها للنجاح المالي وفقاً

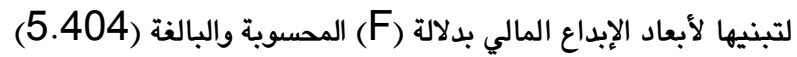

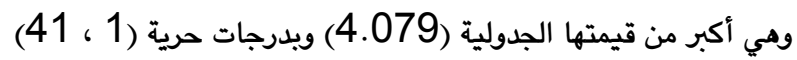
مما يؤكد وجود فروق ذات دلالة احصائية بين مصارف محافظة دهوك تجاه متغير النجاح المالي وفقاً لتبنيها لأبعاد الإبداع المالي بين المصارف المبحوثة. وجاءت في المرتبة الثانية مصارف محافظة أربيل من حيث قيم مستوى المعنوية المحسوية لمتغير النجاح المالي وفقاً لتبنيها لأبعاد الإبداع المالي ويلغت مستوى المعنوية المحسوية

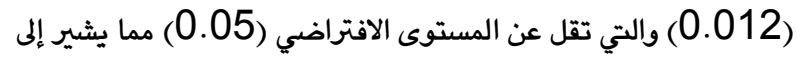




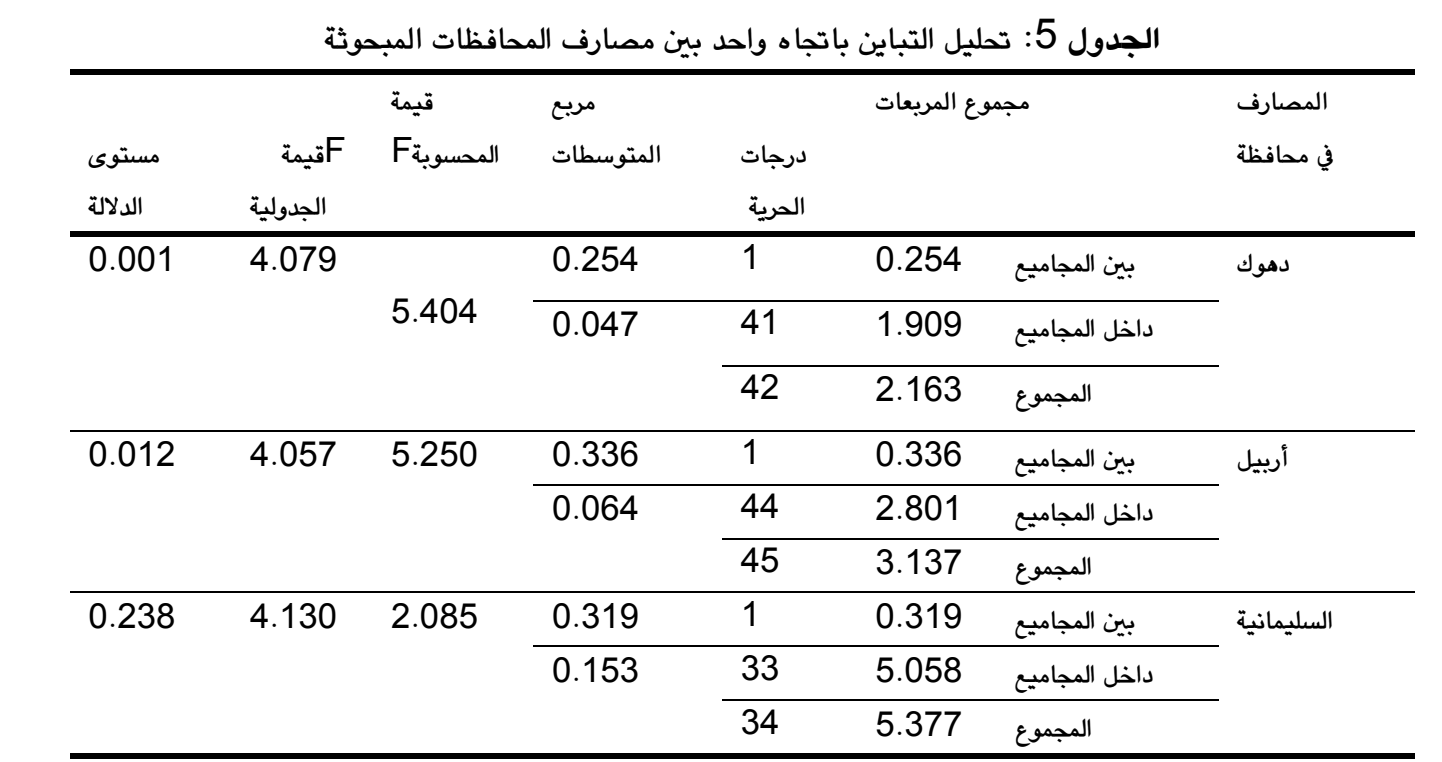

المصدر :من إعداد الباحث بالإعتماد على مخرجات البرمجية الإحصائية (SPSS

4. كشفت نتائج التحليل عن وجود علاقة ارتباط معنوية موجبة ذات دلالة إحصائية بين الإبداع المالي والنجاح المالي إجمالاً على المستوى الميأي

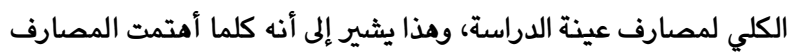

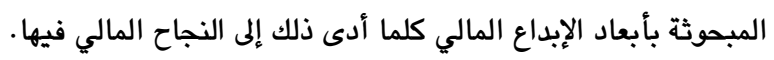

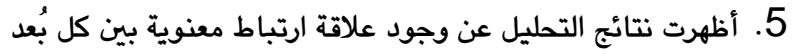
من أبعاد الإبداع المالي والنجاح المالي على المستوى الكلي للمصارف

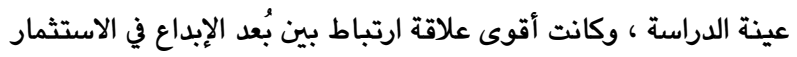

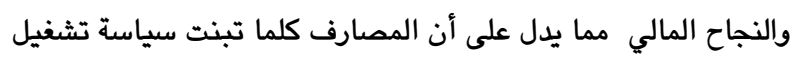
الأموال والبحث عن أفضل الفرص الاستثمارية وتنويع مجالات

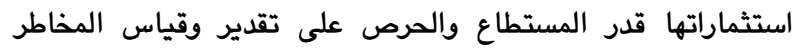

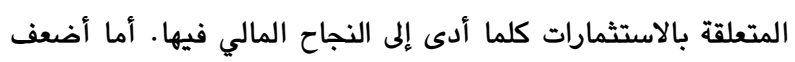

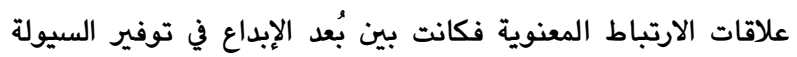

$$
\text { والنجاح المالي. }
$$

6. أظهرت نتائج تحليل الإنحدار البسيط وجود علاقة تأثير معنوية بين متغيرات الدراسة الرئيسة ويمستويات عالية لدى عينة الدراسة،

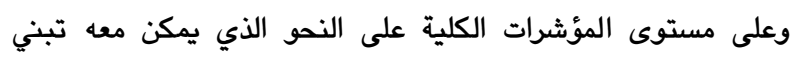

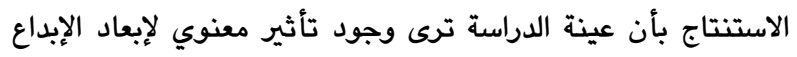

$$
\text { المالي إجمالاً في النجاح المالي. }
$$

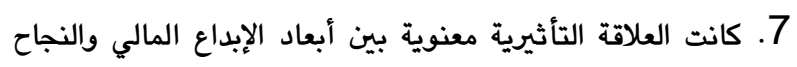

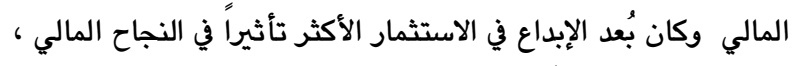

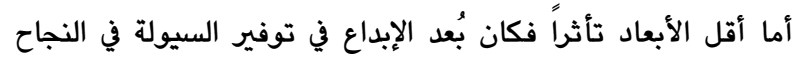

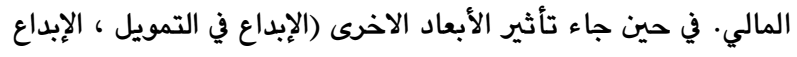

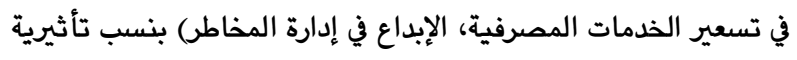

$$
\text { معنوية ومتباينة على التوالي. }
$$

8. أظهرت نتائج تحليل التباين الأحادي إلى وجود تباين تجاه متغير لتاني

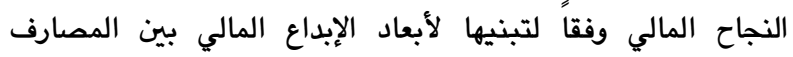

6. المبحث الخامس: الاستنتاجات والمقترحات

يعد هذه الفقرة خلاصة لما توصل إليه هذا البحث من استنتاجات

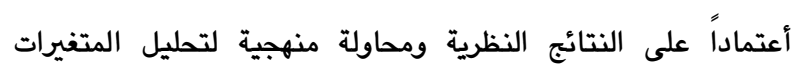
المتمثلة بأبعاد الإبداع المالي ومتطلبات النجاح المالي، وبهذا الاتجاه

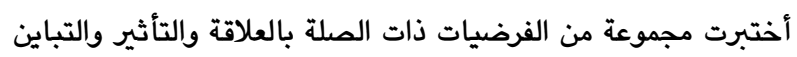

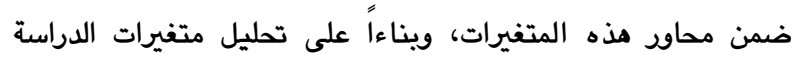
واختبار العلاقات بينها على وفق ما أفضى إليه أنموذج الدراسة. 1.6 - الاستنتاجات: ويتناول أهم الاستنتاجات التي توصل إليها البحث الحالي والتي تتمثل

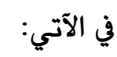

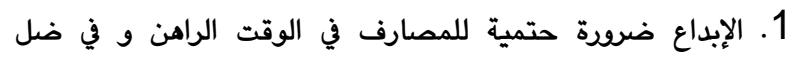
التحولات الاقتصادية الراهنة، ولابد من تجسيد الإبداع المالي وإدارته داخل المصارف عبر تدديد الطاقات الإبداعية ومحاولة تدريبها وتوفير

الظروف الملائمة و المناسبة لاستغلال الطاقات الإبداعية المتاحة.

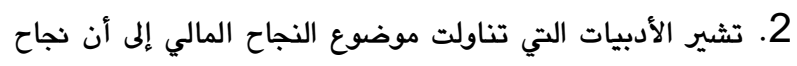
المصارف يتطلبت توفر الخبرات البشرية الكفوءة وكذلك توفر الموارد المالية اللازمة لأنثاء هذه المصارف وتوفر قيادة كفوءة تقوم بتنظيم

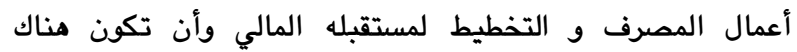
استراتيجية تسويقية لترويج الخدمات المصرفية المقدمة ووجود تكنولوجيا متقدمة لضمان تسهيل سير العمليات المالية ، وكذلك قدرة العاملين في المصارف للوصول إلى المعلومات وتحليلها للتعرف على الفرص والتهديدات التي يواجهها المصرف. 3. يعد النجاح المالي مفهوماً أكثر أتساعاً وقبولاً من مفهوم الإداء التهاء

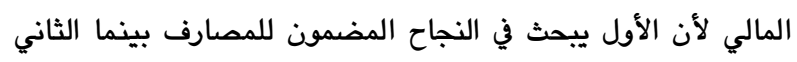
يشير إلى كيفية أداء هذه المصارف لنجاحها. 
استراتيجيات توفير السيولة كون أن هذا البُعد كان الأقل تأثيرًا في النجاح المالي رغم أهميته. 8. على المصارف المبحوثة ويشكل خاص مصارف محافظة السليمانية بتفعيل المنافسة من خلال التركيز على أبعاد الإبداع المالي وذلك بسبب ضعف التباين في النجاح المالي في هذه المحافظة اعتماداً على أبعاد الإبداع المالي. 9. يقترح البحث على المصارف المبحوثة العمل بالمسح السوقي بشكل دوري وذلك من أجل تقديم خدمات جديدة لزبائنها ودراسة شكاوى الزبائن والتعرف على حاجاتهم والأستفادة منها لتحسين جودة الخدمات مستقبلا. 10. تقترح الدراسة على المصارف المبحوثة عينة الدراسة التركيز على خطوات التخطيط المالي والمتمثلة بالتخطيط لمستقبلها

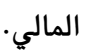

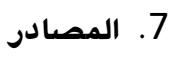

1.7 المصادر باللغة العربية: 1.1.7. الرسائل والأطاريح الجامعية: البيحاني، صالح بن أحمد، (1999)، "العوامل المؤثرة في اتخاذ قرارات

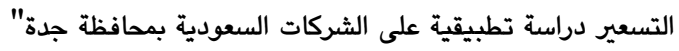
، رسالة ماجستير، إدارة الأعمال، جامعة الملك عبدالعزيز.

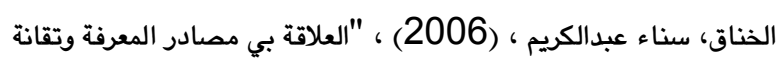

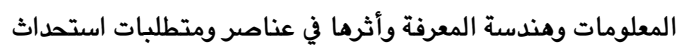
المنظمة الافتراضية" ، اطروحة دكتوراه ، إدارة الأعمال ، كلية الإدارة والاقتصاد ، جامعة المستنصرية.

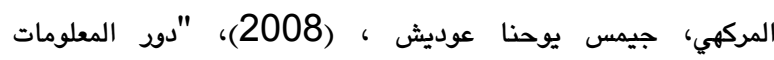

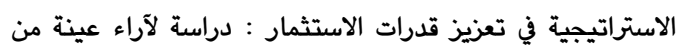

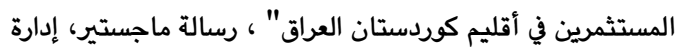
الاعمال، كلية الادارة والاقتصاد، جامعة دهوك.

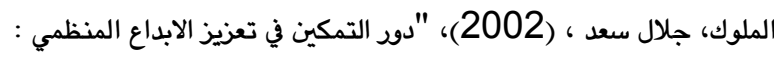

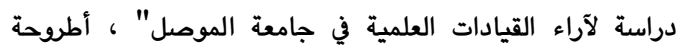
دكتوراه (غير منشوره) ، كلية الإدارة والاقتصاد، جامعة

$$
\text { الموصل. }
$$

2.1.7 . المحلات والدوريات: الجهماني، عيسى، (1999) ، "استخدام النسب المالية للتنبؤ بتعثر المصارف ، دراسة تطبيقية على القطاع المصرفي في الأردن" ، ل

مجلة الإدارة العامة ، العدد (2). الذفاجي، علي جيران عبد علي ، (2012) ، "قياس العلاقة بين ممارسات الإدات العامد (2)، الموارد البشرية والأداء المصري الناجح : دراسة تطبيقية في عينة

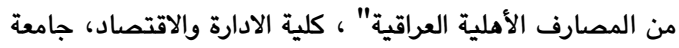
القادسية، مجلة القادسية للعلوم الإدارية والاقتصادية ،المجلد

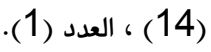

المبحوثة، وجاءت في المرتبة الأولى مصارف محافظة دموك من حيث تباينها للنجاح المالي وفقا لتبنيها لأبعاد الإبداع المالي، وجاءت في المرتبة الثانية مصارف محافظة أربيل من حيث التباين تجاه متغير النجاح المالي وفقاً لتبنيها لأبعاد الإبداع المالي، أما مصارف محافظة السليمانية فقد جاءت بالمرتبة الأخيرة من حيث التباين تجاه متغير النجاح المالي وفقا لتبنيها لأبعاد الإبداع المالي بين المصارف

$$
\text { المبحوثة. }
$$

2.6 2.6 المقترحات: 2

بعد استعراض الاستنتاجات فإنه من الممكن تقديم عدد من التوصيات وعلى ضوء تلك الاستنتاجات فقد تم تقديم بعض التوصيات الضرورية

1. ضرورة المحافظة على مستويات الإبداع المالي والعمل على تطويرها لدى أفراد عينة الدراسة من خلال ورث التدريب أو من خلال العمل والمعايشة الميدانية في مستوى إدارة المصرف كونها من الأساليب المناسبة لرفع وتنمية المهارات المصرفية للمديرين في المصارف المبحوثة. 2. إتاحة الفرصة للمديرين ويكافة مستوياتهم الوظيفية للتعرف على أبعاد الإبداع المالي ومتطلبات النجاح المالي من خلال إقامة الندوات والبرامج التدريبية المتخصصة في هذا المجال، وهذا يسهم في تبادل الآراء والخبرات بين المديرين الممارسين لأعمالهم من جهة وبين أصحاب الخبرات الأكاديمية من جهة أخرى. 3. ضرورة تعزيز التعاون مع الجهات الأكاديمية عبر برامج بحوث مشتركة و تسهيل استخدام التجهيزات المتاحة على مستوى المنظمات والمختبرات الجامعية ،علماً أن هذا التعاون سيعود بالمنفعة على الطرفين ،بحيث تستفيد منظمات الأعمال المالية من النتائج المتوصل إليها في شكل خدمات جديدة وحلول للمشاكل من جهة، ومن جهة أخرى تستفيد الجامعات من الجانب التطبيقي. 4. يقترح البحث على المصارف عينة الدراسة الاهتمام بمتطلبات النجاح المالي وأبعاده وذلك لتحقيق النجاح المالي فيها. 5. يوصي البحث المصارف المبحوثة بتبني سياسة تشغيل الأموال

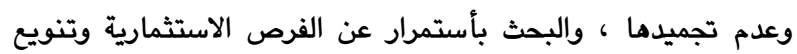

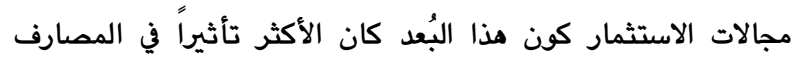
المبحوثة وعليها استغلال نقاط القوة في مذا البُعد.

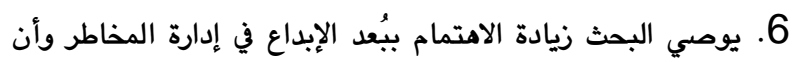
تكون مناك جهة مختصة فيها لإدارة المخاطر للإبداع في العمليات المالية. 7. يقترح البحث الأهتمام ببُعد الإبداع في توفير السيولة وذلك من خلال استغلال فائض السيولة لدى المصرف واعتماد أساليب مالية متطورة ومبدعة لتخطيط السيولة لديها من خلال استحضار مقومات ومرتكزات 
السابق، جروان (1985)، " معجم اللغات " ، دار السابق ، بيوت ، لبنان

سلامة، ابتسام خالد، (2007) ، " القيادة الإدارية الإبداعية السبيل للتميز الإداري " ، ورثة عمل ، الجمعية السعودية للإدارة.

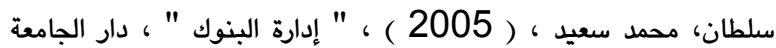
الجديدة ، جامعة الإسكندرية ، مصر.

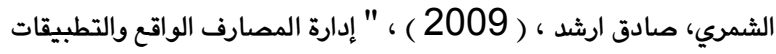

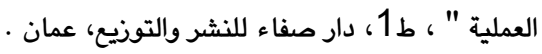

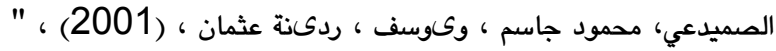

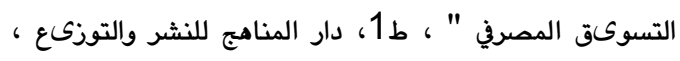
عمان. العامري، صالح مهدي محسن ،الغالبي ،طاهر محسن منصور ، (2008)

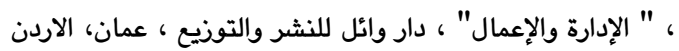

عبيدات، محمد، (2004)، " أساسيات التسعير في التسويق المعاصر:

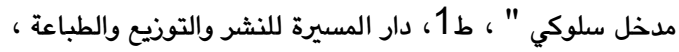
عمان. العزاوي، محمد عبد الوماب ، (2002) ، " " أنظمة إدارة الجودة ISO \& 9000ISO14000 عقل، مفلح محمد، (2011) ، " مقدمة في الإدارة المالية والتحليل المالي

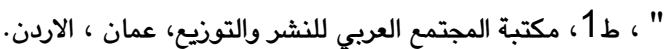

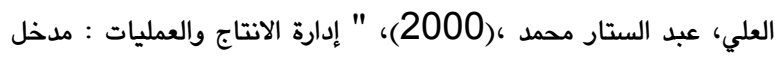
كمي " ، ط1 ، دار وائل للنشر ، عمان.

الفضل، عبد الحسين ، والطائي ، يوسف جحيم سلطان،(2004) ، " "

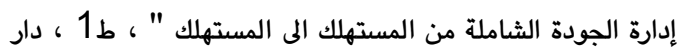

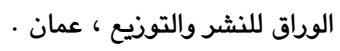

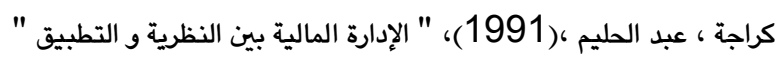

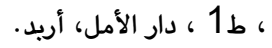

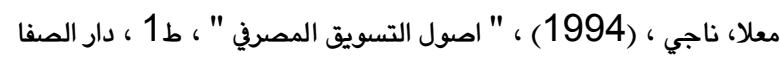

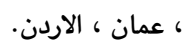

النعيمي، عدنان تايه، والتميمي ، أرشد فؤاد، (2008) ، ل " التحديل

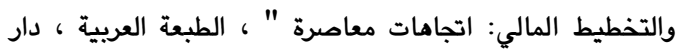
اليانوري العلمية للنشر والتوزيع ، عمان ، الاردن.

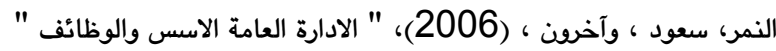
، ط 6 ، مكتبة الشفري للطباعة والتوزيع ، الرياض .

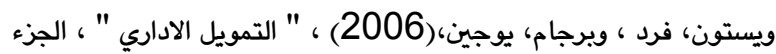

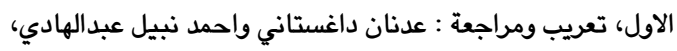

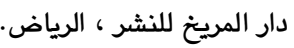

$2.7[$ ـ المصادر باللغة الاجنبية:

\section{A- Scientific Thesis \& Dissertation:}

Bos, Jaap W.B., \& Kolari, James W. , \& Lamoen, Ryan C.R. van, (2009) , "Competition and Innovation: Evidence from Financial Services"
دهام، عبدالستار ابراهيم ، (2007) ، "التعلم المنظمي وأثره في نجاح المنظمات : دراسة ميدانية في شركات وذارة الأعمال والإسكان في

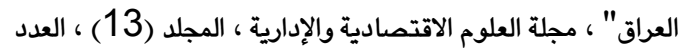

الذهبي، جاسم محمد ، و الطائي ، علي حسون ، (2001) ، "إدارة الاستراتيجية بين رسالة المنظمة وأهدافها: دراسة استطلاعية لأراء عينة من القيادات الإدارية العاملة في المنظمات العراقية " ،

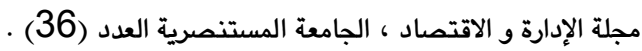

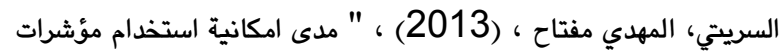
تقييم الأداء في بيئة التصنيع الحديثة في القطاع الصناعي الليبي

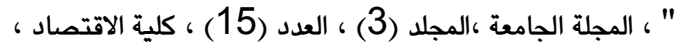

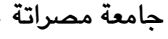

الضمور، ماني حامد،(2003)، "العوامل المؤثرة في تسعير المنتجات

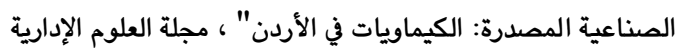

$$
\text { ، المجلد (15) ، العدد (1). }
$$

$$
3.1 .7
$$

البلتاجي، محمد، (2010) ، " تنمية الموارد البشرية في المؤسسات

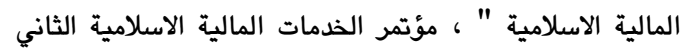
للفترة من 27-28 نيسان ،مصرف ابو ظبي الاسلامي، مصر. 4.1.7 أبو حمد ، رضا صاحب، (2002)، " إدارة المصارف، مدخل تحليلي كمي معاصر"، ط1 ، دار الفكر للطباعة والنشر والتوزيع، الأردن.

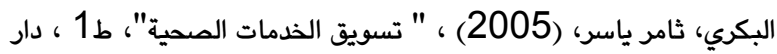
اليازوري العلمية للنشر والتوزيع،عمان، الاردن. الجميل، سرمد كوكب ، (2012)، " المدخل إلى إدارة المؤسسات المالية

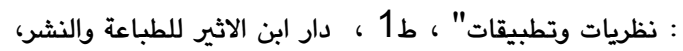

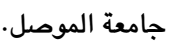

الجميل، سرمد كوكب ،(2008) ، " التمويل الدولي : مدخل في الهياكل

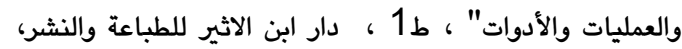

$$
\text { جامعة الموصل جامعة الموصل. }
$$

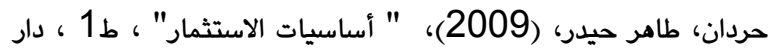
المستقبل للنشر والتوزيع، عمان ، الاردن. حريوش، حسني وأرشيد، عبد المعطى،(1996) ، " الاستثمار والتمويل بين النظرية والتطبيق " ، ط1، جامعة العلوم التطبيقية، الأردن.

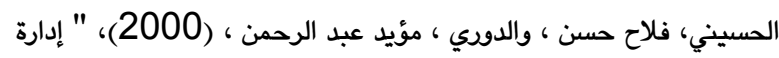

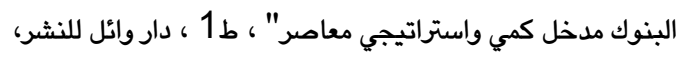

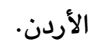
الخضيري، محسن ، (1999) ، " ألتسويق المصرفي مدخل متكامل

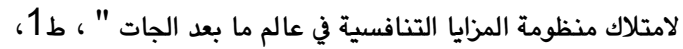

$$
\text { دار زهران للنشر ، عمان. }
$$

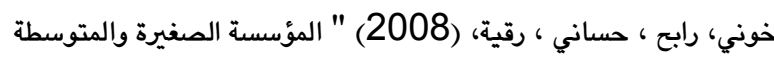

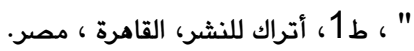


Robert W. \& Worsham, C. Bruce, (2004), Foundation of Financial Planning, An Overview, The American college.

Nuiruri, James Kamau \& Ngari, James Mark, (2014), " Effects of Financial Innovations on the Financial Performance of Commercial Banks in Kenya", International Journal of Humanities and Social Science, Vol. 4, No. 7,May.

Pitman, F. (2008). Internet cafe entrepreneurs: pioneers in information dissemination in Indonesia. The International Journal of Entrepreneurship and Innovation, Vol. 4, No. 4, 251-263.

Thurik, M., (2007), " Policy Induced Constraints on Small Enterprise Development in Asian Developing Countries: Small Enterprise Development", Journal of Small Business, Vol. 5, No. 2, 66-78.

Verhees, F. J. H. M., \& Muhlenberg, M. T. G., (2009), "Market Orientation, Innovativeness, Product Innovation, and Performance in Small Firms. Journal of Small Business Management, Vol. 42, No. 2, 25-38.

Vilkinas T, Cartan G and Saebel J., (2011), "Business Success Factors", DKCRC Research Report 79. Ninti One Limited, Alice Springs.

Weiss, Michal Grinstein\& Sherraden, Margaret S., (2014), " Starting Early for Financial Success: Capability into Action", The Journal of Consumer Affairs and the Financial Literacy and Education Commission announce a, Special Issue.

\section{C- Conferences \& Workshope:}

Frame, W. Scott, \& White, Lawrence J., (2002), " Empirical Studies of Financial Innovation: Lots of Talk, Little Action?" , Prepared for the Conference on "Innovation in Financial Services and Payments"Federal Reserve Bank of Philadelphia May 16-17.

\section{D- Books:}

Bartol, Kathryn K. / Nartin, C. D.,(1991), "Management", New York: McGraw-Hill Inc.

Brigham, Eugene F. \& Ehrhardt, Michael C., (2005) "Financial Management Theory and Practice", R.R. Donnelley Willard, 11th Edition.

Daft , Richard L. , (2000), " Management" , 5th Ed , Thomson south Western, U.S.A.

Daft, Rechard, (2001), "Organizational Behavior", Harcourt College Publishers, USA.

Daft, Richard .L., ( 2001), "Organization theory and Design " New Yourk "South Western.

Emery, Douglas R., Finnerty, John D., \& Stowe, John D., (2007), "Corporate Financial Management", 3rd Ed, Pearson Prentice Hall, U.S.A

Heizer, Jay; \& Render, Barry, (2004), Principles of Operations Management, 5th ed., Pearson Prentice Hall, New Jersey.

Hempel, George H. \& Simouson, Donald G \& Coleman , Alan B., (1994)," Bank Management", 4th ed. , John Wiley \& Son's Inc. U.S.A
Utrecht School of Economics ,Utrecht University, Texas, U.S.A.

Weaver, Dian N. ,(2008), "Leadership Characteristics of Dietetic Professionals in Ohio" The Degree of Master, Ohio University .

\section{B- Journal \& Periodical:}

Avais, Mohammed, (2014), " Financial Innovation and Poverty Reduction" International Journal of Scientific and Research Publications, Volume 4, Issue 1, January.

Bruno, Giancarlo \& Lippe, Stefan , (2012), " Rethinking Financial Innovation : Reducing Negative Outcomes While Retaining The Benefits", World Economic Forum , 91-93 route de la Capite CH-1223 Cologny/Geneva Switzerland.

Btach, Joanna , (2011), " Financial Innovations and Their Role in The Modern Financial System Identification and Systematization Of The Problem" , Ministry Of Science and Higher Education , Financial Internet Quarterly ,eFinanse" 2011, Vol (7), No (3).

Butler, J. C., (2008), "Psychometric Theory", New York: McGraw-Hill, Journal of Market Research Society Vol (24), No (2), p 98-122.

Conger ,M., (2002), " Leadership : Learning to share the Vision , Organizational dynamics", winter Vol . 19, issue 3 .

Cristian , (2012), "Financial Instability and Financial Innovations, Economy Transdisciplinarity Cognition", Vol. 15, Issue 2.

Curran, M. , (2007), "Family enterprises as an important factor of the economic development: the case of Slovenia", Journal of Enterprising Culture, Vol.11, No.2, p111-130.

Dabic , M., Cvijanovic, V., Gonzalez-Loureiro, M., (2011), "Keynesian, Post-Keynesian Versus Schumpeterian, Neo-Schumpeterian. An Integrated Approach to the Innovation Theory", Management Decision, Vol.49, No.2,

Hayes, R., Pisano, G., (1996), "Manufacturing strategy: at the intersection of two paradigm", Production and Operations Management, Vol. 5 No.1, pp.12-20.

Holden, L,J, Hyde,R.and K.Brasier, (2004), " Building on our strengths workforce Development for the pensylvania DairyIndustry", Economic Review. 3(21).

Jasra, Javed Mahmood \& Khan, Muhammad Asif \& Hunjra, Ahmed Imran \& Rehman, Rana Aziz Ur. \& Azam ,Rauf, (2011), "Determinants Of Business Success Of Small and Medium Enterprises", International Journal of Business and Social Science, Vol. 2 No. 20 :274-280 .

Kock, M. Mc Grath, (2003), " Improving Labor productivity: Human Resource Management policies do Matter" strategic Management Journal 17 .

Krishnan,V.R, (2005), " Leader-Member Exchange", Trans Formational Leadership and value system, EIBO, Vol(10)(1) , 14-20 . Cooper, 
Peter F. , (2003), "Christoffersene Elements of Financial Risk Management", Academic Press; USA.

Shafer, Scott M.; \& Meredith, Jack R.,(1998), "Operations Management: A process Approach with Spreadsbeets", John Wiley \& Sons, Inc.

Stevenson, William J., (2005), " Operations Management ", 8th ed., McGraw-Hill.

Van Home, James \& John, Wachowicz,(1995), Fundamentals of Financial Management, 9th Ed., Prentice Hall.

Walker, Orville C. , et. al, (1999), " Marketing Strategy : Planning and Implementation", 3rd Ed , McGraw-Hill, Irwin, Singapore.

Webster's Merriam Co., (1974), USA.

\section{E- Studies From Internet:}

Gubler, Z. J. , (2010), " Instruments, Institutions and the Modern Process of Financial Innovation ", Obtained from, http://ssrn.com/abstract= 1608409 .

Pantu, Nick, (2010), " Whats This financial Planning All About", prim time Financial Counsellors P/L., www.deakin.edu.au

Roger, (2005), " Sustainable success : Seven pates ", roger@sevenpaths.com, http://sevepaths.htm
Hitt, Michael \& Ireland, Duame \& Hoskisson, Robert, (2001), " Strategic Management" South Western college Publishing, USA.

Jones , Gareth R. \& George, Jennifer M., (2006), "Contemporary Management" , 4th Ed , McGraw-Hill, Irwin, new York.

Keegan, Mary, (2004), "Management of Risk Principles and Concepts" Hm Treasury, The Orange Book, Working Papers.

Krajewski, Lee J.; \& Ritzman, Larry P.,(1999), Operations Management : Strategy and Analysis", 5th ed., Addison-Wesley Longman, Inc., U.S.A

Llewellyn, D. T. ,(2009), " Financial Innovation and the Economics of Banking and the Financial System" In: L. Anderloni, D. T. Llewellyn, R. H. Schmidt, "Financial Innovation in Retail and Corporate Banking" Cheltenham: Edward Elgar.

Mac millan, Hugh \& tampoe, mahan, (2000), " strategic management : process ", control and implement tation, of and press inc.

Nickels, William G., Mchugh, James M. and Mchugh Susan M., (2002), "Understanding Business", Mc Graw - Hill Companies, Inc .

OECD, (2003), Creativity, Innovation and Economic Growth in the 21st Century. Business and Industry Advisory Committee to the OECD. 


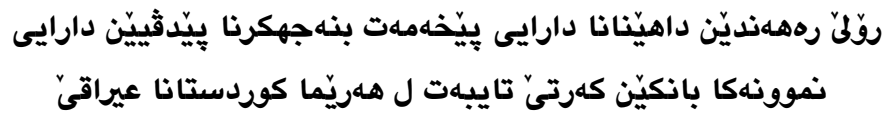

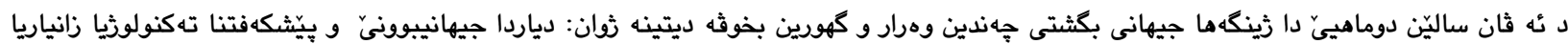

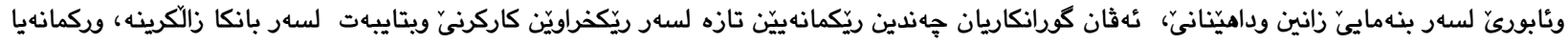

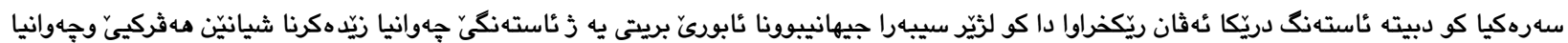

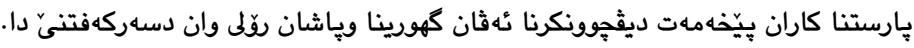

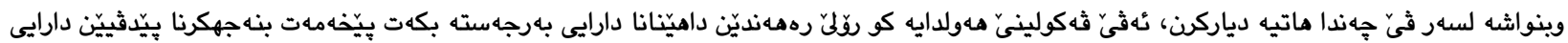

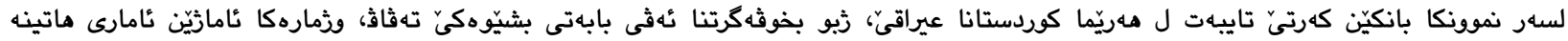

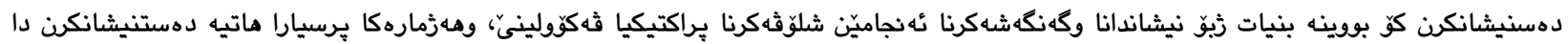
بيته سنوورهك بوّ ئاريشا ثهكولينى ويثى نَاواييّ ل خاريّا:

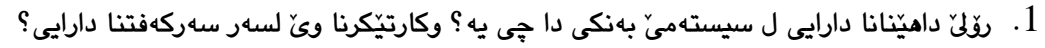

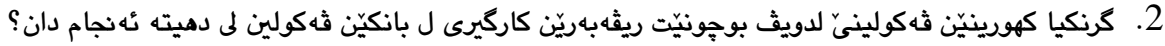
ئه ثه ثكولينه كههشتيه كومهكا دهرئه نجاما وكرنكترييّن ثورانا:

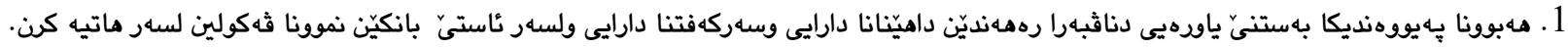

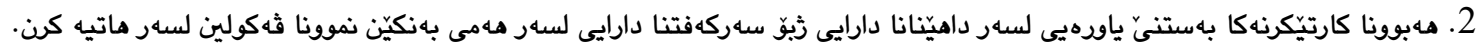

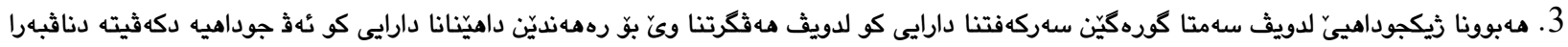

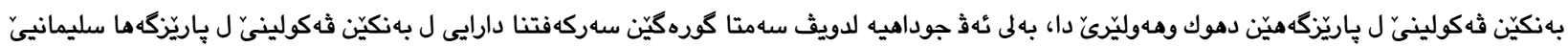
دا نهبوو. و ثهكولينيّ هزمارهكا راسيّارده داناينه بهردهست تايبهت ب بانكين ثهكولين لسهر هاتيه ئهنجام دان، سهرهراى بِيشنياركرنا كومهكا ثهولينيّن نَاينده بو ثهكولوران دثى بوارى دا.

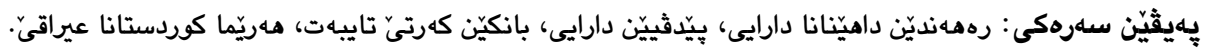

\title{
Investigated the Role of Financial Innovation Dimensions in Achieving Financial Success Requirements in A Sample of Private Banks in The Kurdistan Region of Iraq
}

\begin{abstract}
In the last two decades, the world witnessed many developments and changes, including: globalization, the progress of information technology, and innovation and knowledge-based economy. These changes imposed new challenges for business organizations and the private banks. So, how to increase their competitiveness and maintaining it and succeeding in it became the key challenges for these organizations due to these changes and advances.

Based on the foregoing the current study investigated the role of financial innovation dimensions in achieving financial success requirements in a sample of private banks in the Kurdistan Region of Iraq. which calculated a number of statistical indicators that formed the basis for the presentation and discussion of the results. A number of research questions were specified for the problem of the study and they were as follows:

1. Whether there is a correlation between financial innovation dimensions and requirements of financial success in the surveyed Almassa?

2. The extent of the impact of the relationship between financial innovation and the requirements of the dimensions of financial success in the surveyed banks?

The study reached a number of conclusions, most important of which were :

1. The results of the analysis showed that there was a significant correlation between every dimension of financial innovation and financial success at the macro level in the surveyed banks.

2. There was a significant effect of financial innovation on the overall financial success throughout the surveyed banks.

3. There was discrepancy towards financial success variable according to the adoption of the dimensions of financial innovation among the surveyed banks in the provinces of Dohuk, and Erbil, whereas results showed that there was no such discrepancy among the surveyed banks in the province of Sulaymaniyah.

The study gave a number of recommendations consistent with the findings of the current study, as well as proposed a set of future studies for researchers in the field.

Keywords: Financial Innovation Dimensions, Financial Success Requirements, Private Banks, The Kurdistan Region of Iraq.
\end{abstract}

